\title{
Degradation of selenoprotein S and selenoprotein K through PPARY- mediated ubiquitination is required for adipocyte differentiation
}

\author{
Jea Hwang Lee ${ }^{1,2} \cdot$ Jun Ki Jang ${ }^{1} \cdot$ Kwan Young Ko ${ }^{1}$ Yunjung Jin ${ }^{1} \cdot$ Minju Ham ${ }^{1} \cdot$ Hyunwoo Kang ${ }^{1}$ Ick Young Kim ${ }^{1}$
}

Received: 29 January 2018 / Revised: 6 July 2018 / Accepted: 18 July 2018 / Published online: 6 August 2018

(c) ADMC Associazione Differenziamento e Morte Cellulare 2018

\begin{abstract}
Adipocyte differentiation is known to be related with endoplasmic reticulum (ER) stress. We have reported that selenoprotein S (SelS) and selenoprotein $\mathrm{K}$ (SelK) have a function in the regulation of ER stress and ER-associated degradation. However, the association between adipocyte differentiation and the ER-resident selenoproteins, SelS and SelK, is unclear. In this study, we found that the levels of SelS and SelK were decreased during adipocyte differentiation and were inversely related to the levels of peroxisome proliferator-activated receptor $\gamma(\operatorname{PPAR} \gamma)$, a central regulator of adipogenesis. It has been recently reported that PPAR $\gamma$ has E3 ubiquitin ligase activity. Here, we report that PPAR $\gamma$ directly interacts with both SelS and SelK via its ligand-binding domain to induce ubiquitination and degradation of the selenoproteins. Lysine residues at the 150th position of SelS and the 47th and 48th positions of SelK were the target sites for ubiquitination by PPAR $\gamma$. We also found that adipocyte differentiation was inhibited when either SelS or SelK was not degraded by PPAR $\gamma$. Thus, these data indicate that PPAR $\gamma$-mediated ubiquitination and degradation of SelS and SelK is required for adipocyte differentiation.
\end{abstract}

\section{Introduction}

Obesity has been recognized as one of the most serious public health problems [1]. An increased adipocyte number (hyperplasia) and/or size (hypertrophy) contributes to development of obesity and its related insulin resistance [2]. Both adipocyte number and size determine the lipid storage capacity of the body in humans. When the demand for lipid storage exceeds its capacity, the

\section{Edited by R.A. Knight}

These authors contributed equally: Jea Hwang Lee, Jun Ki Jang.

Electronic supplementary material The online version of this article (https://doi.org/10.1038/s41418-018-0180-x) contains supplementary material, which is available to authorized users.

\section{Ick Young Kim}

ickkim@korea.ac.kr

1 Division of Life Sciences, Korea University, 145 Anam-Ro, Seongbuk-Gu, Seoul 02841, Republic of Korea

2 Present address: Molecular Neurogenetics Unit, Center for Genomic Medicine, Massachusetts General Hospital, and Department of Neurology, Harvard Medical School, Boston, MA 02114, USA number of adipocytes increases through proliferation and/or adipocyte differentiation from pre-adipocytes [3, 4]. In vitro adipocyte differentiation from 3T3-L1 cells is mediated by a well-programed cascade of transcriptional events, which are induced by the activation of major transcription factors, including the CCAAT/enhancer binding protein family and peroxisome proliferatoractivated receptor $\gamma(\operatorname{PPAR} \gamma)[5,6]$. PPAR $\gamma$ is an essential and sufficient transcriptional regulator needed to differentiate adipocytes from their precursor cells $[7,8]$. When PPAR $\gamma$ is activated, the expression of lipid synthesis- and differentiation-related genes is increased, including the expression of CCAAT/enhancer-binding protein $\alpha(\mathrm{C} / \mathrm{EBP} \alpha)$, fatty acid synthase, lipoprotein lipase, and fatty acid-binding protein [9, 10]. Preadipocyte factor-1, a pre-adipocyte-specific inhibitor of adipogenesis, is transcriptionally suppressed by activation of PPAR $\gamma$ [11].

PPAR $\gamma$ is subjected to various post-translational modifications [12]. Phosphorylation, sumoylation, and polyubiquitination on specific regions of PPAR $\gamma$ are related to its transcriptional activity and stability [13, 14]. It has recently been reported that PPAR $\gamma$ acts as an E3 ubiquitin ligase through its cysteine (Cys) residue at the 139th position [15]. Its function as an E3 ubiquitin ligase, that induces 
the ubiquitination of substrates, is independent of its transcriptional activity. So far, nuclear factor- $\mathrm{\kappa B} / \mathrm{p} 65$ and mucin1 C-terminal subunit are known to be ubiquitinated and degraded by PPAR $\gamma[15,16]$.

It has been reported that endoplasmic reticulum (ER) stress and ER resident selenoproteins are associated with adipocyte differentiation and PPAR $\gamma$ activation $[17,18]$. When ER homeostasis is disrupted, misfolded proteins are accumulated in the ER, which subsequently activates the unfolded protein response (UPR) [19]. The expression of UPR-related-proteins, such as glucose-regulated protein 78 (GRP78), X-box binding protein 1 (XBP1), and ER-resident selenoproteins [selenoprotein S (SelS) and selenoprotein $\mathrm{K}(\mathrm{SelK})$ ] are induced by ER stress. These ER stress response proteins are involved in restoration of ER stress through proper protein folding, ER-associated protein degradation (ERAD), or ER stress-mediated apoptosis [20-22]. XBP1, a transcription factor of UPR, is involved in the signaling pathway of adipocyte differentiation by up-regulating PPAR $\gamma$ transcription in the early phase of adipogenesis, which contributes to enhanced adipocyte differentiation [23]. SelS, also known as a valosin containing protein (VCP)interacting membrane protein, is an ER membrane selenoprotein that contains a single selenocysteine (Sec, U) at position 188 , which is the penultimate C-terminal residue. SelK is another ER membrane selenoprotein that also contains a single $\mathrm{Sec}$ at position 92 as the penultimate C-terminal residue [24]. Both SelS and SelK are important components of the ERAD complex and interact with the p97/VCP. It is known that both SelS and SelK regulate ERAD and play a role in cell survival $[21,22]$.

Although the mechanism is still unknown, a recent study suggests that SelS inhibits adipocyte differentiation and that SelS is degraded during conditioned medium induced-adipocyte differentiation from 3T3-L1 cells [18]. However, the role of SelK in adipocyte differentiation has not yet been studied. In this study, we investigated the role of both SelS and SelK and their degradation mechanism during adipocyte differentiation. The protein levels of these two ER-resident selenoproteins were dramatically decreased in the early phase of 3T3-L1 cell differentiation, while the level of PPAR $\gamma$ was increased. Thus, there was an inverse relationship between these two selenoproteins and PPAR $\gamma$. We also found that SelS and SelK were ubiquitinated by the E3 ligase activity of $\operatorname{PPAR} \gamma$, and then degraded during adipogenesis. The degradation of both SelS and SelK was essential for adipogenesis. These results indicate that PPAR $\gamma$-mediated ubiquitination and degradation of SelS and SelK is required for adipocyte differentiation.

\section{Results}

\section{Protein levels of SelS and SelK are reduced during} adipogenesis of 3T3-L1 pre-adipocytes

It has been reported that expression of SelS and SelK is increased by ER stress in various cell types [25-27]. Like GRP78, the promoter region of both SelS and SelK contains an ER stress response element, which is a consensus binding site for regulating the ER stress response [28, 29]. We previously reported that both SelS and SelK, components of the ERAD complex, interact with the p97/VCP protein and are involved in cell survival during ER stress $[21,22]$. It has been suggested that ER stress-related proteins, such as XBP1 [23], protein kinase RNA-like ER kinase, inositol-requiring enzyme 1 alpha [20], and SelS are associated with adipogenesis and obesity [30]. During differentiation of 3T3-L1 pre-adipocytes induced by adipogenic cocktail containing dexamethasone (Dex) treatment, SelS is degraded; this degradation is necessary for adipogenesis [18]. However, the role of the ER-resident selenoproteins or their regulatory mechanism in adipocyte differentiation remains unclear. To investigate the role of SelS and SelK, we first measured their expression at both transcriptional and translational levels during adipogenesis. Adipocyte differentiation from 3T3-L1 cells was determined by monitoring intracellular lipid accumulation after staining the cells with oil red O (ORO) (Fig. 1a). We observed that the mRNA levels of PPAR $\gamma$ and C/EBP $\alpha$, which are key regulators of adipogenesis were increased during adipocyte differentiation (Fig. 1b, c). The mRNA levels of ER stress-related genes, such as GRP78, spliced XBP1, SelS, and SelK were also increased (Fig. 1d-g). The protein level of GRP78 gradually increased from day 1 to day 8. Consistent with a previous report [31], PPAR $\gamma$ expression increased from day 1 to day 4, and then decreased (Fig. 1h). However, levels of both SelS and SelK significantly decreased from day 1 to 6 , and then recovered on day 8 (Fig. 1h). These results show that even though the mRNA levels of SelS and SelK are increased during adipocyte differentiation, their protein levels are decreased; this decrease shows an inverse relationship with the levels of PPAR $\gamma$. These results also suggest that both SelS and SelK are post-translationally regulated during adipogenesis.

\section{Degradation of both SelS and SelK proteins is dependent on expression of PPARy}

Dex in an adipogenic cocktail is an essential requirement for differentiation of 3T3-L1 preadipocytes, and induces the degradation of SelS during adipogenesis [18]. To investigate how SelS is degraded, and whether SelK is also 
Fig. 1 Both SelS and SelK protein levels are decreased during 3T3-L1 early differentiation. a Differentiating cells were fixed at days $0,1,2$, 4,6 , and 8. Intracellular lipid droplets in differentiated adipocytes were stained with ORO for image analysis (left panel). ORO-stained lipid droplets were extracted for quantification of lipid accumulation as described in the Materials and methods section (right panel). Differentiating cells were also harvested at days $0,1,2,4,6$, and 8 for analysis of mRNA levels of PPAR $\gamma(\mathbf{b}), \mathrm{C} /$ EBP $\alpha(\mathbf{c})$, GRP78 (d), spliced XBP1 (sXBP1) (e), SelS (f), and SelK (g) by real-time RT-PCR. $\beta$-actin was used for normalization. h Differentiating cells were harvested at indicated days, and then cells were analyzed by western blotting (left panel). Whole cell lysates were detected by indicated antibodies. PPAR $\gamma$ expression is represented as a fold of induction of control (right panel). All graphs indicated the results from three independent experiments. The error bars represent \pm S.D., and the $p$ values represent comparisons with the control $(* * * p<0.001$ $* * p<0.005, * p<0.05$ compared to day 0 ) a

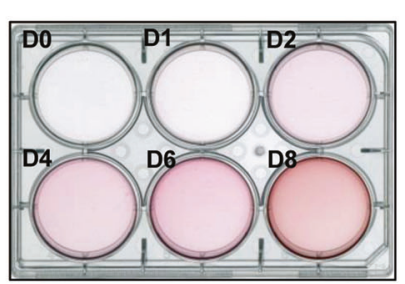

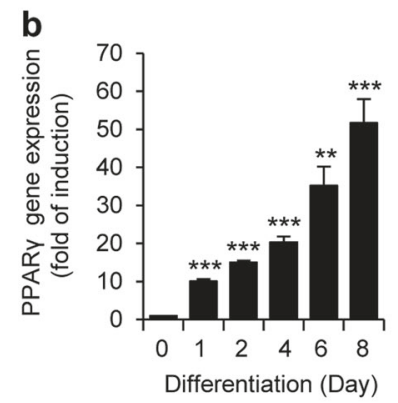
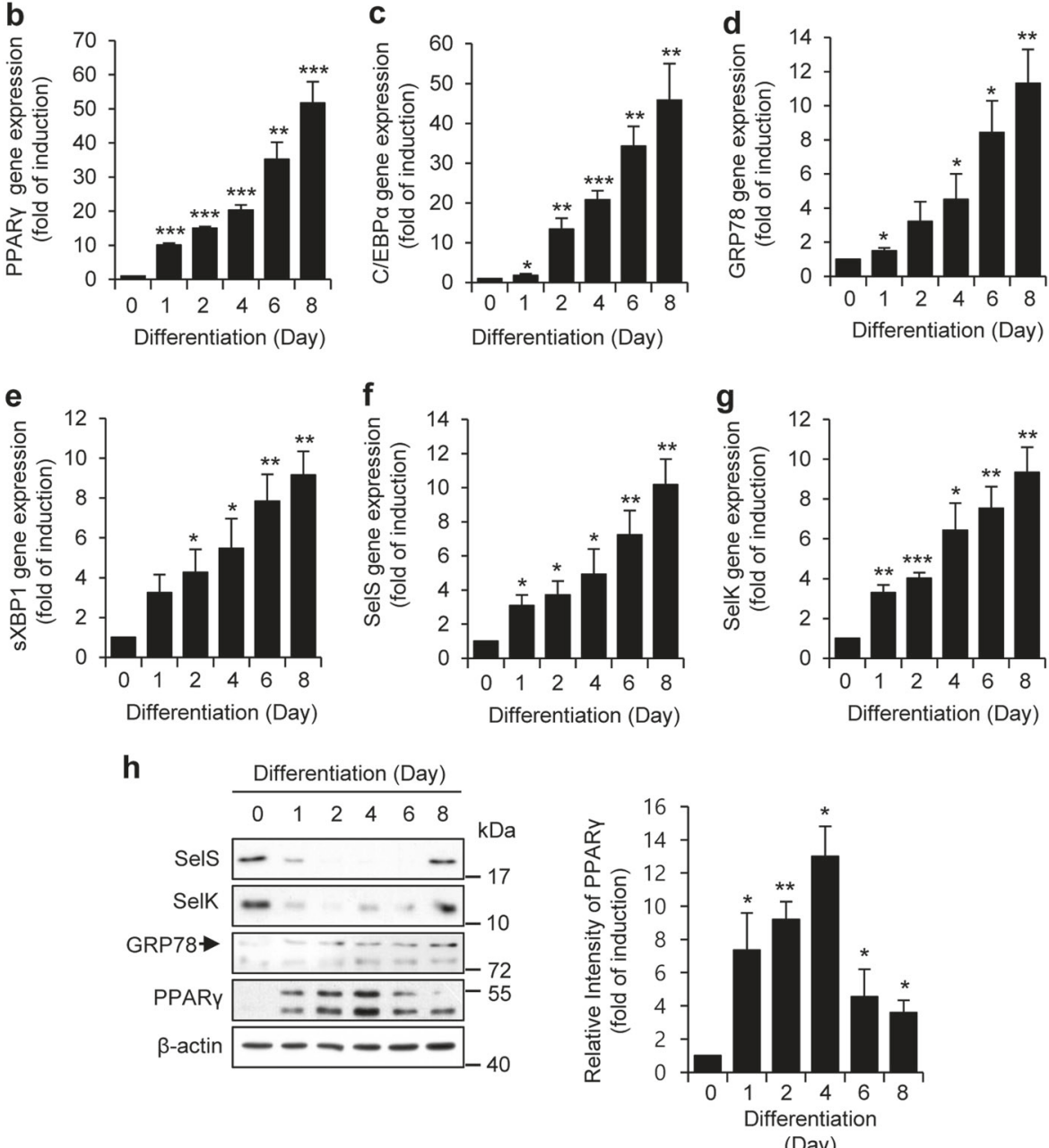

(Day)

degraded during adipogenesis, differentiation from 3T3-L1 cells was induced using adipogenic medium in the presence or absence of Dex. As shown in Fig. 2a, both SelS and SelK were degraded in the presence of Dex. To test how the proteins were degraded, we first determined ubiquitination of the selenoproteins in the presence or absence of a proteasome inhibitor (MG132). Ubiquitination of both SelS and SelK was observed after treatment with MG132 (Fig. 2b, d). In the absence of MG132, their protein levels were significantly decreased. Although cells were treated with MG132, when cells were cultured without Dex, SelS and SelK, they were neither ubiquitinated nor showed any decrease in their protein levels (Fig. 2c, e). As shown in
Fig. 2a-e, PPAR $\gamma$ was expressed in the presence of Dex, and the protein level of PPAR $\gamma$ was inversely related to the amount of SelS and SelK during adipogenesis (Fig. 1h). Recently, E3 ligase activity of PPAR $\gamma$ has been reported $[15,16]$. Hence, we hypothesized that expression of PPAR $\gamma$ might promote ubiquitin-dependent protein degradation of both SelS and SelK, regardless of the presence of Dex. To examine this, the human colon cancer cell line (HT29) and the human breast adenocarcinoma cell line (MCF7) were used. It has been known that HT29 cells constitutively express relatively high amounts of $\operatorname{PPAR} \gamma$, whereas MCF7 cells express lower amounts than other cells [15, 32]. As shown in Fig. 2f, the protein level of PPAR $\gamma$ in HT29 cells 
a

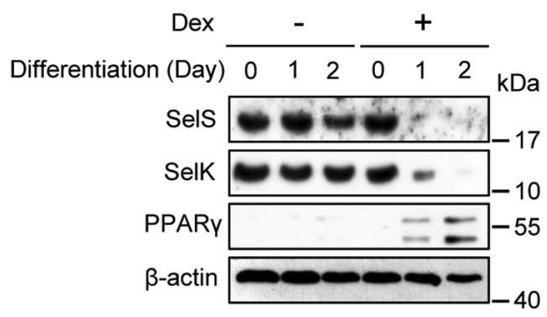

d

Differentiation (Day) $\quad 0 \quad 1 \quad 1$

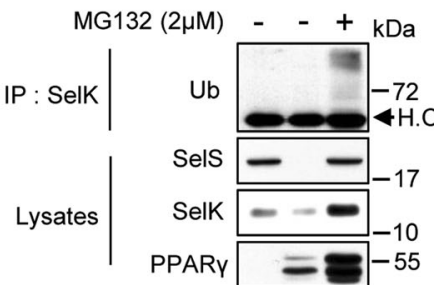

f

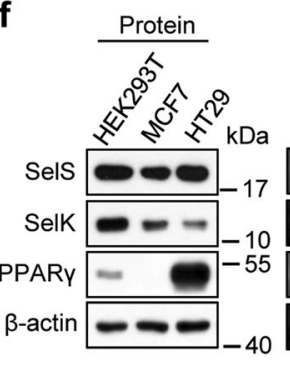

h

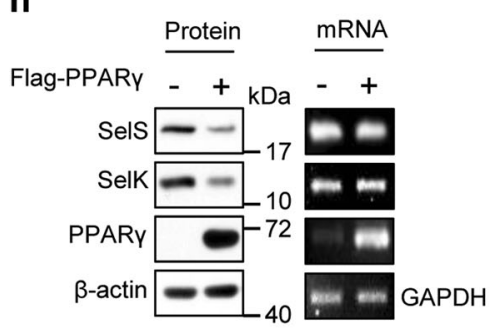

GAPDH b

Differentiation (Day) $\quad 0 \quad 1 \quad 1$

IP : SelS

Lysates

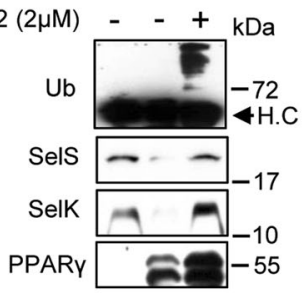

C

Dex $\frac{\text { Day1 }}{-\quad+}$

MG132 $(2 \mu \mathrm{M})++\mathrm{kDa}$

IP : SelS

Lysates

$\mathrm{Ub}$

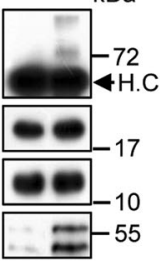

e

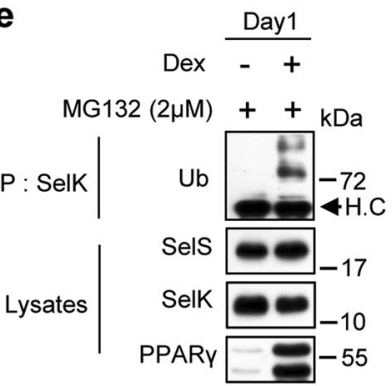

g
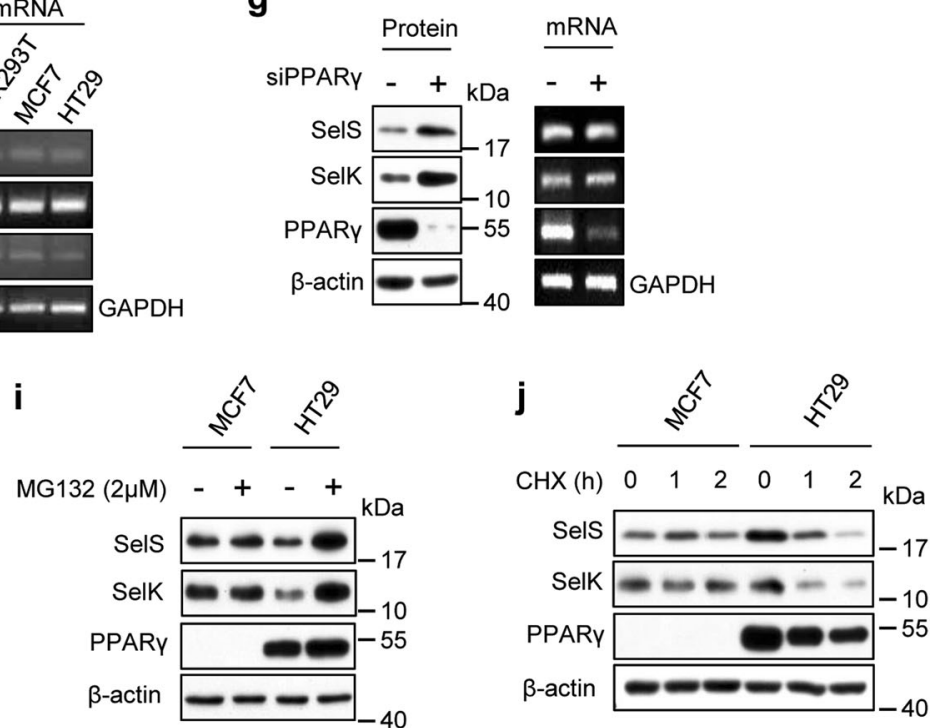

Fig. 2 Degradation of both SelS and SelK proteins is dependent on PPAR $\gamma$ expression. a 3T3-L1 pre-adipocytes were incubated in adipogenic medium containing IBMX and insulin, in the presence and absence of Dex for indicated days. Whole cell lysates were detected by indicated antibodies. b, d 3T3-L1 pre-adipocytes were incubated in adipogenic medium containing IBMX, insulin and Dex for 1 day. These cells were then treated with or without $2 \mu \mathrm{M}$ MG132 for $12 \mathrm{~h}$. c, e 3T3-L1 pre-adipocytes were incubated in adipogenic medium containing IBMX, insulin, in the presence and absence of Dex for 1 day. These cells were treated with $2 \mu \mathrm{M} \mathrm{MG132}$ for $12 \mathrm{~h}$. Lysates and immunoprecipitation samples [anti-SelS (c), anti-SelK (e)] were analyzed by western blotting with the indicated antibodies. HC heavy chain, IP immunoprecipitation, Ub ubiquitin. f The indicated cells were lysed, and then whole cell lysates were analyzed by western blotting using indicated antibodies (left panel). Total RNAs isolated from indicated cells were subjected to RT-PCR analysis of PPAR $\gamma$,

SelS, SelK, and GAPDH mRNA (right panel). g HT29 cells were transfected with siPPAR $\gamma$ or control siRNA. Whole cell lysates were assessed by western blotting using indicated antibodies (left panel). Total RNAs isolated from HT29 cells transfected with siPPAR $\gamma$ or control siRNA were subjected to RT-PCR analysis of SelS, SelK, PPAR $\gamma$, and GAPDH mRNA (right panel). h MCF7 cells were transfected with siPPAR $\gamma$ or control siRNA. Whole cell lysates were assessed by western blotting using indicated antibodies (left panel). Total RNA isolated from MCF7 cells transfected with Flag-PPAR $\gamma$ or pCMV-tag2b vector was subjected to RT-PCR analysis of SelS, SelK, PPAR $\gamma$, and GAPDH mRNA (right panel). i The indicated cells were treated with $2 \mu \mathrm{M}$ MG132 for $12 \mathrm{~h}$. These cells were analyzed by western blotting. Whole cell lysates were detected by indicated antibodies. j MCF7 and HT29 cells were treated with $10 \mu \mathrm{g} / \mathrm{mL}$ CHX for the indicated times. Whole cell lysates were analyzed by western blotting with the indicated antibodies 


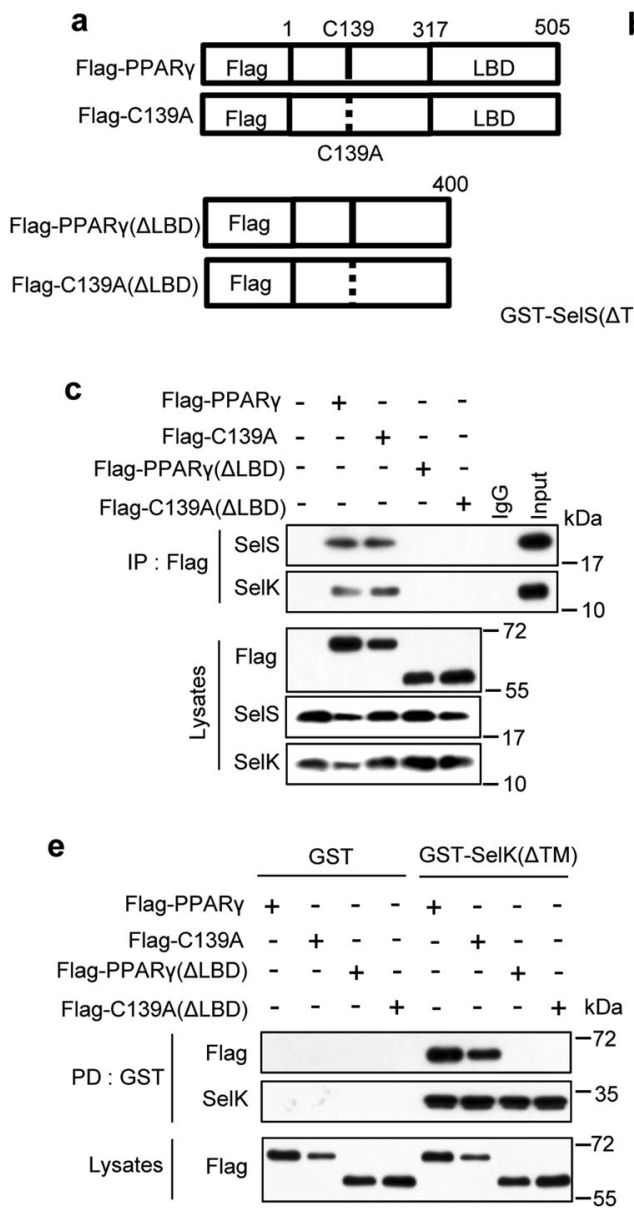

Fig. 3 PPAR $\gamma$ directly binds to SelS and SelK. a Organization of PPAR $\gamma$ is schematically represented. Flag is the N-terminal-tagged Flag. LBD is the ligand-binding domain region. The location of the Cys ${ }^{139}$ residue is indicated by a vertical bar, and the location of Cys ${ }^{139}$ changed to Ala is indicated by a dotted-vertical bar. b The above two constructs display the schematic representation of SelK organization, and the two constructs below represent SelS. TM is the transmembrane region. HA-TEV is the N-terminal-tagged HA-TEV, and GST is the N-terminal-tagged GST. The location of the Sec or the Sec changed to Cys residue is indicated by vertical bar. Coiled-coil is the coiled-coil domain, His is the N-terminal-tagged His. c MCF7 cells were transfected with Flag-PPAR $\gamma$, Flag-C139A, Flag-PPAR $\gamma(\Delta$ LBD), or Flag-

was higher than that in MCF7 cells, whereas the mRNA levels of PPAR $\gamma$ were not different. When HT29 cells were transfected with siRNA of PPAR $\gamma$ (siPPAR $\gamma$ ), the protein levels of both SelS and SelK were increased compared with control cells, whereas their mRNA levels remained unchanged (Fig. 2g). In addition, we also found that FlagPPAR $\gamma$-transfected MCF7 cells showed decreased protein levels of both SelS and SelK without change in their mRNA levels (Fig. 2h). Protein levels of SelS and SelK in MCF7 cells were unchanged in both untreated cells and in cells treated with MG132 for $12 \mathrm{~h}$. However, their levels in HT29 cells were increased by MG132 treatment (Fig. 2i). To understand the relationship between the levels of these two
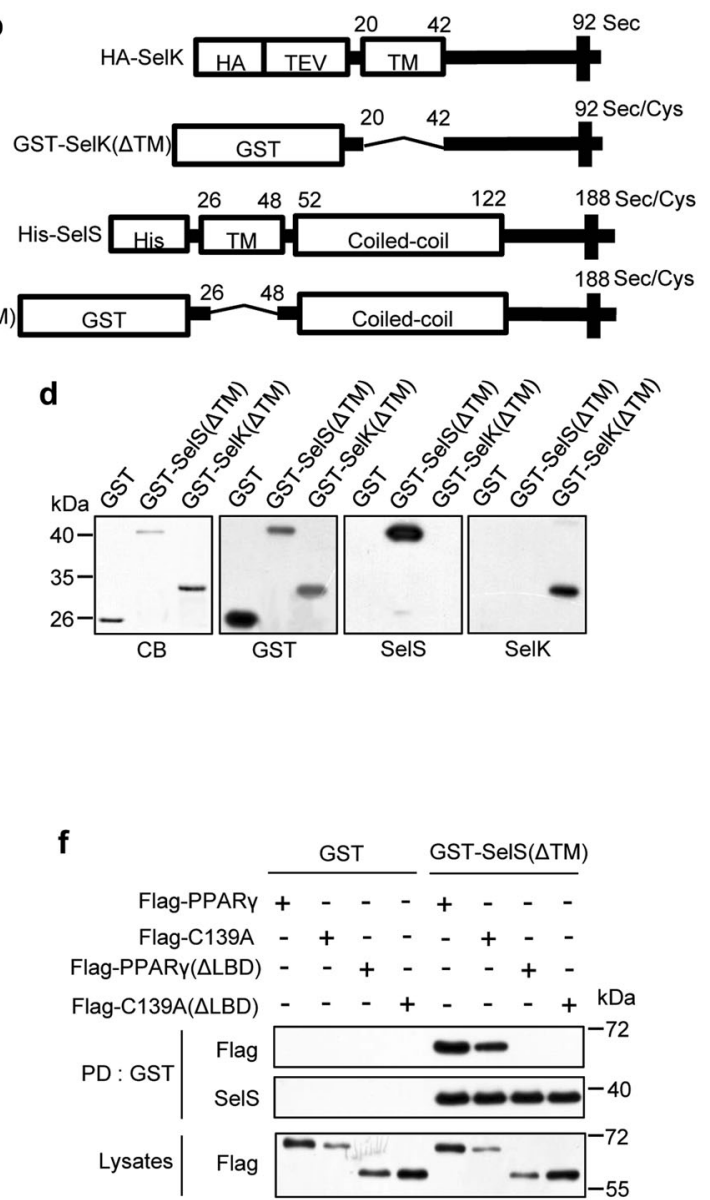

C139A $(\Delta \mathrm{LBD})$ for $24 \mathrm{~h}$. Lysates and immunoprecipitation samples (anti-Flag and anti-IgG) were analyzed by the indicated antibodies. Cell lysates (5\% input) were used as positive control. IP immunoprecipitation, Ub ubiquitin. d GST and GST fusion proteins [GST$\operatorname{SelS}(\Delta \mathrm{TM})$, GST-SelK $(\Delta \mathrm{TM})]$ were purified and visualized by Coomassie Blue staining and western blotting (anti-GST, anti-SelS, and anti-SelK). CB coomassie blue staining. e, f Purified proteins were incubated with MCF7 cell lysates in which Flag-PPAR $\gamma$, Flag-C139A, Flag-PPAR $\gamma(\Delta \mathrm{LBD})$, or Flag-C139A( $\Delta$ LBD) was overexpressed, followed by GST pull-down using glutathione beads. Each mixture and lysate was analyzed by Western blotting with the indicated antibodies. PD GST pull-down

selenoproteins and expression of PPAR $\gamma$, the levels of SelS and SelK in MCF7 and HT29 cells were determined using a cycloheximide (CHX) chase assay. As shown in Fig. 2j, both SelS and SelK were not degraded in MCF7 cells, but were degraded in HT29 cells within $2 \mathrm{~h}$. Since PPAR $\gamma$ is well known as a ligand-activated nuclear receptor [33], we investigated the effect of PPAR $\gamma$ ligand on the degradation of SelS and SelK. When HT29 cells were treated with rosiglitazone, a thiazolidinedione class PPAR $\gamma$ ligand, the mRNA level of C/EBP $\alpha$ was increased (Supplementary fig. S1a). However, protein levels of both SelS and SelK were not affected by the ligand (Supplementary fig. S1b and c). These results suggest that degradation of both SelS and 


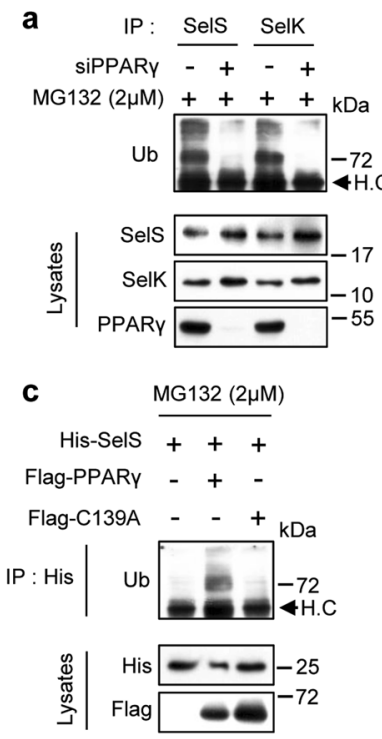

\section{b}
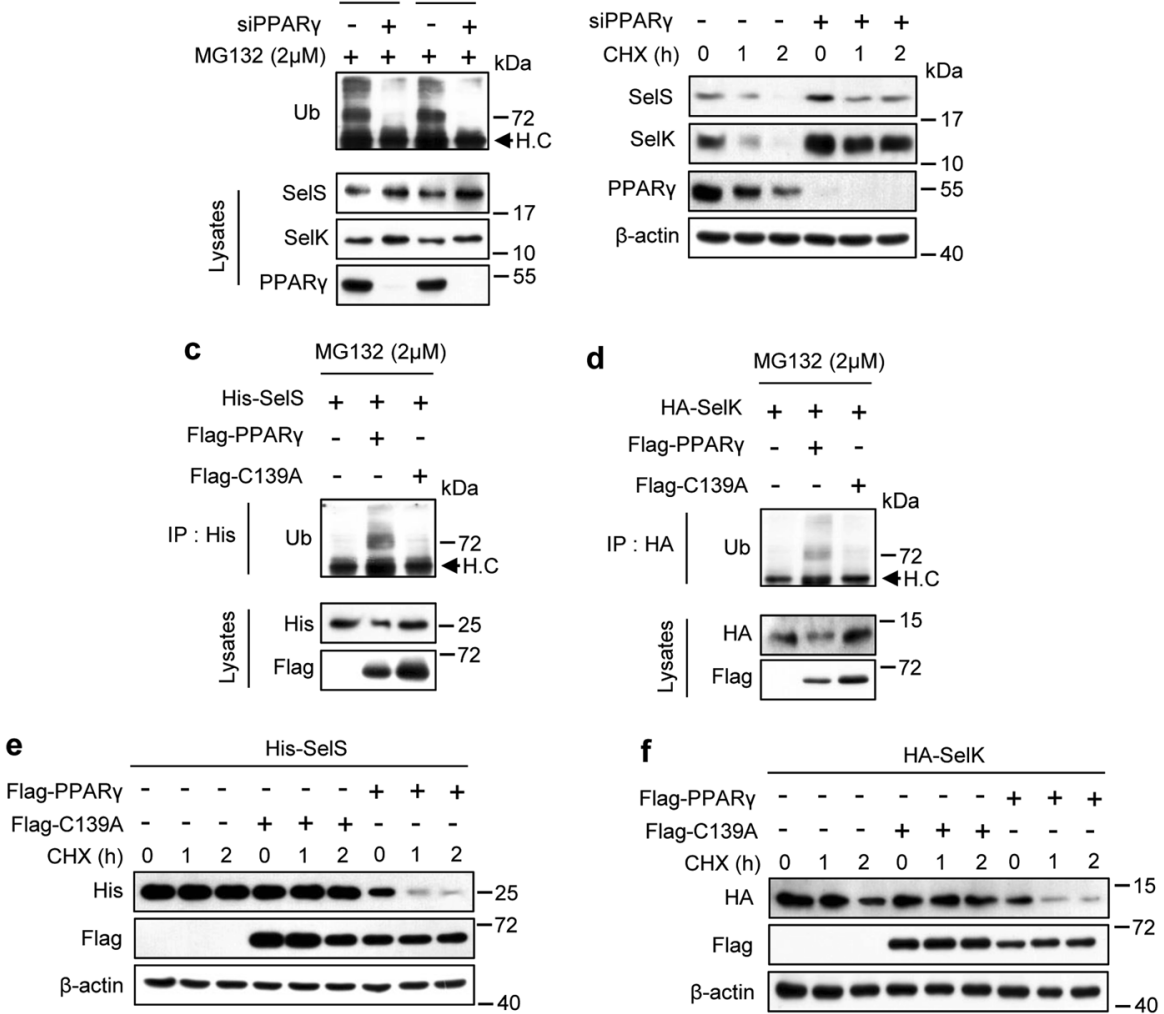

Fig. 4 Both SelS and SelK are ubiquitinated by PPAR $\gamma$. a HT29 cells were transfected with siPPAR $\gamma$ or control siRNA for $48 \mathrm{~h}$, and then treated with $2 \mu \mathrm{M}$ MG132 for $12 \mathrm{~h}$. Lysates and immunoprecipitation samples (anti-SelS and anti-SelK) were analyzed by western blotting with the indicated antibodies. b HT29 cells were transfected with siPPAR $\gamma$ or control siRNA for $48 \mathrm{~h}$. These cells were treated with $10 \mu \mathrm{g} / \mathrm{mL} \mathrm{CHX}$ for indicated times. Whole cell lysates were analyzed by western blotting with the indicated antibodies. c MCF7 cells were co-transfected with His-SelS and Flag-PPAR $\gamma /$ Flag-C139A or HisSelS alone for $48 \mathrm{~h}$. d MCF7 cells were co-transfected with HA-SelK and Flag-PPAR $\gamma /$ Flag-C139A or HA-SelK alone for $48 \mathrm{~h}$. c, d These

SelK during adipogenesis is dependent on PPAR $\gamma$ expression regardless of its activation by ligand.

\section{SelS and SelK are ubiquitinated and degraded by the E3 ligase activity of PPARY}

We investigated whether the reduced intracellular level of SelS and SelK proteins during adipogenesis was due to ubiquitination and degradation induced by the E3 ligase activity of PPAR $\gamma$. To do this, the interactions between both selenoproteins and PPAR $\gamma$ were first determined using plasmids containing PPAR $\gamma$, SelS, or SelK, as shown in Fig. 3a, b. Since the Cys residue at position 139 on PPAR $\gamma$ is an essential amino acid for E3 ligase activity [15], a mutant in which Cys was changed to alanine (Ala) was also constructed. Under basal conditions, Flag-PPAR $\gamma$ and Flag-C139A were bound to both endogenous SelS and

cells were treated with $2 \mu \mathrm{M}$ MG132 for $12 \mathrm{~h}$. Lysates and immunoprecipitation samples [anti-His (c), anti-HA (d)] were analyzed by western blotting with the indicated antibodies. HC heavy chain, IP immunoprecipitation, UB ubiquitin. e MCF7 cells were transfected with His-SelS for $16 \mathrm{~h}$ and then transfected with Flag-PPAR $\gamma$ or FlagC139A. f MCF7 cells were transfected with HA-SelK for $16 \mathrm{~h}$ and then transfected with Flag-PPAR $\gamma$ or Flag-C139A. e, f At $32 \mathrm{~h}$ after the 1 st transfection, cells were treated with $10 \mu \mathrm{g} / \mathrm{mL} \mathrm{CHX} \mathrm{for} \mathrm{indi-}$ cated times. Whole cell lysates were analyzed by western blotting with the indicated antibodies

SelK (Fig. 3c). However, ligand-binding domain (LBD) deletion mutants of PPAR $\gamma$, Flag-PPAR $\gamma(\Delta \mathrm{LBD})$ and Flag-C139A( $\triangle \mathrm{LBD})$, did not bind to either endogenous SelS or SelK. LBD is the essential domain for PPAR $\gamma$ to bind its substrate. The interaction between endogenous PPAR $\gamma$ and the selenoproteins was not impacted by PPAR $\gamma$ ligand-activation (Supplementary fig. S1c). To determine whether PPAR $\gamma$ interacted with SelS and SelK directly, a glutathione S-transferase (GST) pull-down assay was performed with purified GST, GST-tagged SelS and SelK. To increase the efficiency of purification, we deleted the transmembrane (TM) region on both SelS and SelK, generating GST-SelS $(\Delta \mathrm{TM})$ and GST-SelK $(\Delta \mathrm{TM})$, respectively (Fig. 3b). These purified proteins were expressed in Escherichia coli (Fig. 3d). After pre-incubating the purified proteins with MCF7 cell lysates containing overexpressed Flag-PPAR $\gamma$ or indicated mutants of PPAR $\gamma$, each mixture 
a

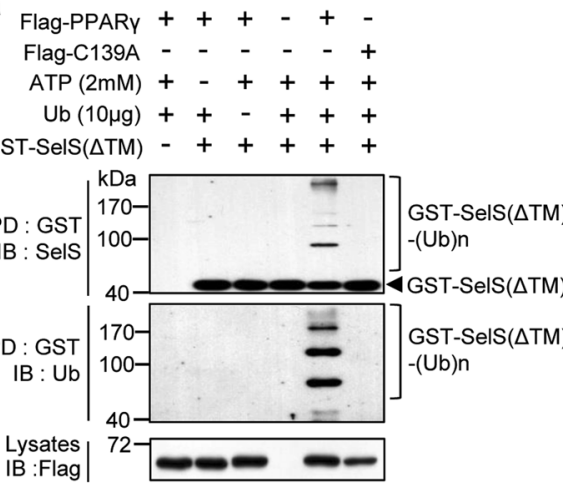

C

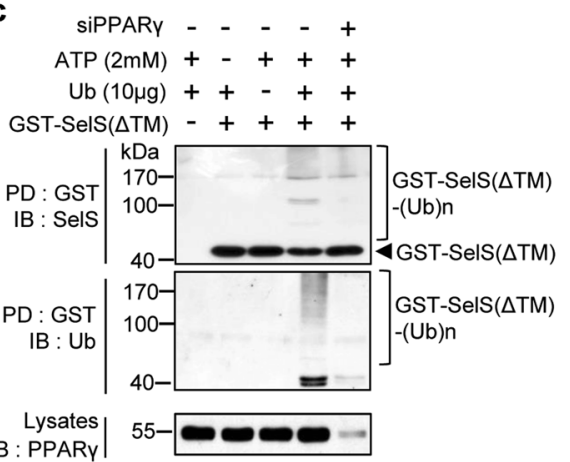

Fig. 5 E3 ligase activity of PPAR $\gamma$ is required for SelS and SelK ubiquitination in vitro. a, b MCF7 cells were transfected with FlagPPAR $\gamma$ or Flag-C139A. Lysates and purified GST fusion proteins [GST-SelS $(\Delta \mathrm{TM})$ (a), GST-SelK $(\Delta \mathrm{TM})$ (b)] were incubated with $2 \mathrm{mM}$ ATP and $10 \mu \mathrm{g}$ ubiquitin in the absence or presence of FlagPPAR $\gamma$ or Flag-C139A, as indicated. Reaction mixtures were boiled in $0.5 \%$ SDS to disrupt protein interaction, followed by GST pull-down using glutathione beads. Lysates and GST pull-down samples were analyzed by western blotting using indicated antibodies. c, d HT29

was incubated with glutathione beads, followed by elution with reduced glutathione. Protein interaction was then determined by western blot analysis. As shown in Fig. 3e, f, GST-SelS $(\Delta T M)$ and GST-SelK $(\Delta T M)$ interacted with Flag-PPAR $\gamma$, as well as Flag-C139A. However, neither GST-SelS $(\Delta \mathrm{TM})$ nor GST-SelK $(\Delta \mathrm{TM})$ interacted with the LBD deletion mutants of PPAR $\gamma$. These results suggest that LBD is critical for direct interaction of PPAR $\gamma$ with these two selenoproteins, regardless of the E3 ligase active site of PPAR $\gamma$.

Next, we determined whether the E3 ligase activity of $\operatorname{PPAR} \gamma$ could induce ubiquitin/proteasome-dependent degradation of both SelS and SelK. As described above, HT29 cells produce relatively more PPAR $\gamma$, and MCF7 cells produce less PPAR $\gamma$ compared to other cells (Fig. 2f). Both SelS and SelK proteins were not ubiquitinated and showed decreased degradation rate in the absence of PPAR $\gamma$ in HT29 cells (Fig. 4a, b). Ubiquitination of His-SelS or HA-SelK was observed in MCF7 cells transfected with Flag-PPAR $\gamma$, but not in cells transfected with Flag-C139A

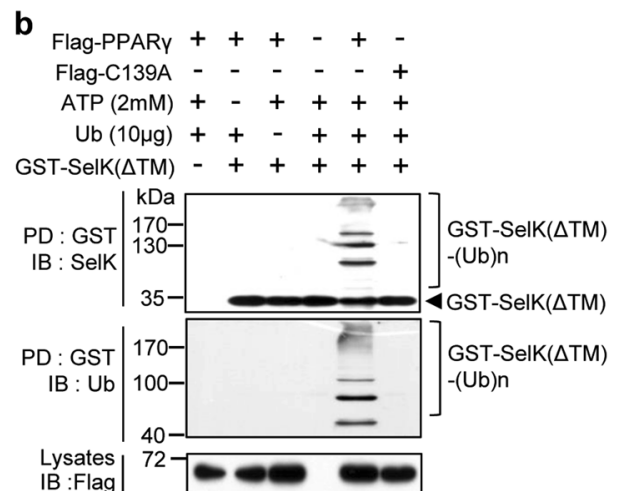

d

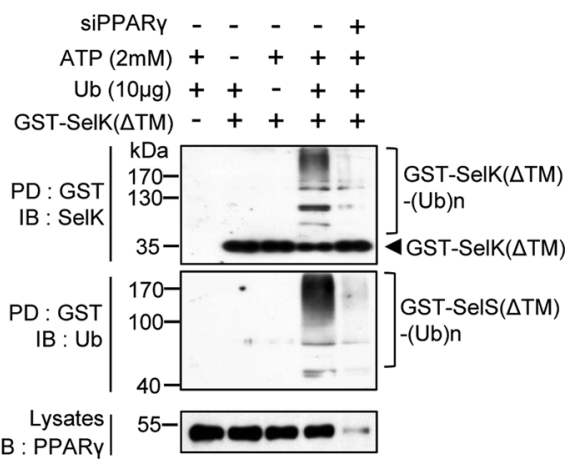

cells were transfected with siPPAR $\gamma$ or control siRNA. Lysates and purified GST fusion protein [GST-SelS $(\Delta \mathrm{TM})(\mathbf{c})$, GST-SelK $(\Delta \mathrm{TM})$ (d)] were incubated with $2 \mathrm{mM}$ ATP and $10 \mu \mathrm{g}$ ubiquitin in the absence and presence of siPPAR $\gamma$ or control siRNA, as indicated. Reaction mixtures were boiled in $0.5 \%$ SDS to disrupt protein interaction, followed by GST pull-down using glutathione beads. Lysates and GST-pull-down samples were analyzed by western blotting using indicated antibodies. PD GST pull-down, IB immunoblot, -(Ub)n conjugated poly-ubiquitin

(Fig. 4c, d). His-SelS or HA-SelK was significantly degraded in MCF7 cells expressing Flag-PPAR $\gamma$. However, degradation of His-SelS or HA-SelK was not observed in MCF7 cells transfected with Flag-C139A (Fig. 4e, f). These results indicate that the E3 ligase-active form of PPAR $\gamma$ containing the Cys residue at the 139th position is necessary for ubiquitination and degradation of both SelS and SelK.

To further confirm the E3 ligase activity of PPAR $\gamma$ on both SelS and SelK, ubiquitination analysis was carried out using an in vitro ubiquitin assay, as described in the Materials and methods section. Poly-ubiquitination of GST-SelS $(\Delta \mathrm{TM})$ or GST-SelK $(\Delta \mathrm{TM})$ was induced by Flag-PPAR $\gamma$, but not by Flag-C139A even in the presence of ATP and ubiquitin (Ub) (Fig. 5a, b). Poly-ubiquitination of GST-SelS $(\Delta \mathrm{TM})$ or GST-SelK $(\Delta \mathrm{TM})$ was observed during PPAR $\gamma$ expression. However, poly-ubiquitination was not detected in the PPAR $\gamma$ knockdown condition (Fig. 5c, d). Taken together we suggest that PPAR $\gamma$ interacts with both SelS and SelK and that these selenoproteins 


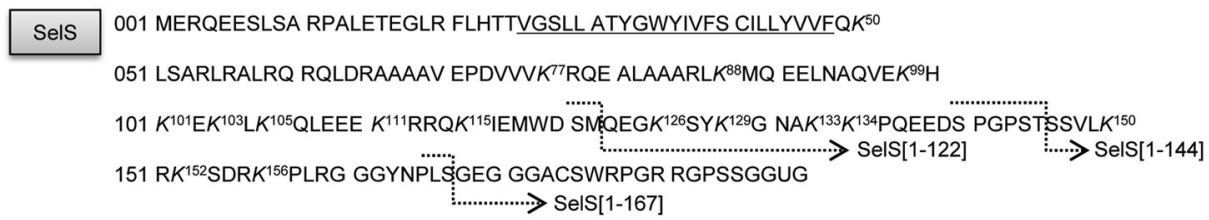

b

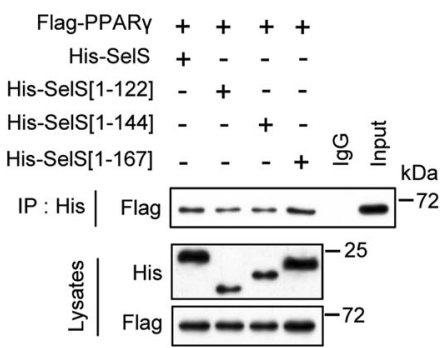

d

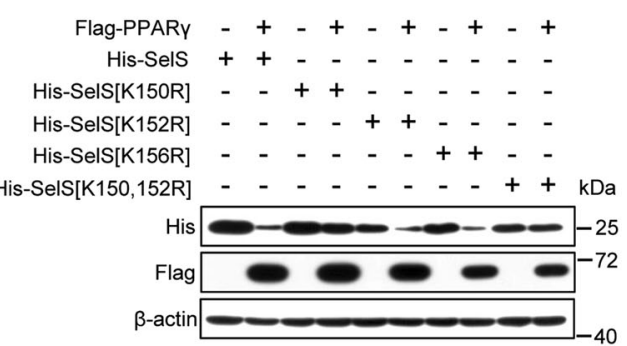

C

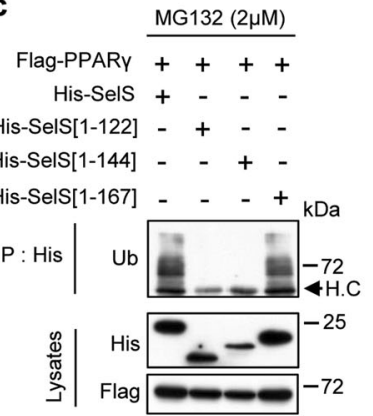

e

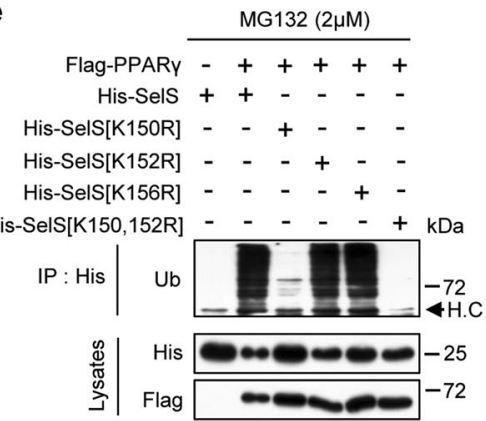

Fig. $6 \mathrm{Lys}^{150}$ of SelS is required for PPAR $\gamma$-mediated ubiquitination. a Amino acid sequence of SelS is represented. The following elements of residues and domains are marked: italic letters (Lys residues), under lined letters (TM region). The construction of SelS mutants, His-SelS (1-122), His-SelS(1-144), and His-SelS(1-167) has been described in the Materials and methods section. b MCF7 cells were co-transfected with Flag-PPAR $\gamma$ and His-SelS or the truncation mutants of SelS for $48 \mathrm{~h}$. Lysates and immunoprecipitation samples (anti-His and anti$\mathrm{IgG})$ were analyzed using the indicated antibodies. Cell lysates $(5 \%$ input) were used as positive control. c Transfected MCF7 cells, under

are ubiquitinated and degraded by the E3 ligase activity of PPAR $\gamma$.

\section{Lys ${ }^{150}$ of SelS is required for PPARY-mediated ubiquitination}

Next, we tried to identify the ubiquitination site of SelS mediated by PPAR $\gamma$. To do this, we determined the region (s) of SelS that bind to PPAR $\gamma$ using three truncation mutants of His-SelS as shown in Fig. 6a. All mutants could interact with Flag-PPAR $\gamma$ (Fig. 6b). However, ubiquitination only occurred in MCF7 cells transfected with His-SelS or His-SelS[1-167] (Fig. 6c). This result indicates that lysine (Lys) residues at 150th, 152nd or 156th position on the cytosolic tail of SelS may be ubiquitinated by PPAR $\gamma$. same conditions as (b), were treated with $2 \mu \mathrm{M}$ MG132 for $12 \mathrm{~h}$. Lysates and immunoprecipitation samples (anti-His) were analyzed by western blotting with the indicated antibodies. d MCF7 cells were transfected with Flag-PPAR $\gamma$, His-SelS or Lys-to-Arg mutants of SelS for $48 \mathrm{~h}$. Whole cell lysates were analyzed by western blotting using indicated antibodies. e Transfected MCF7 cells, under same conditions as (d), were treated with $2 \mu \mathrm{M}$ MG132 for $12 \mathrm{~h}$. Lysates and immunoprecipitation samples (anti-His) were analyzed by western blotting with the indicated antibodies. HC heavy chain, IP immunoprecipitation

To identify the specific site for ubiquitination of SelS, each Lys residue was changed to arginine (Arg). Flag-PPAR $\gamma$ mediated degradation and ubiquitination levels of His-SelS [K152R] and His-SelS[K156R] were same as His-SelS; however those levels of His-SelS[K150R] and His-SelS [K150, 152R] were significantly decreased (Fig. 6d, e). These data suggest that the Lys residue at the 150th position of SelS is poly-ubiquitinated by PPAR $\gamma$ and this ubiquitination is required for protein degradation.

\section{Both Lys ${ }^{47}$ and Lys ${ }^{48}$ of SelK are required for PPARY- mediated ubiquitination}

In addition to SelS, we also tried to identify the ubiquitination sites of SelK induced by the E3 ligase activity of 
a

SelK 001 MVYISNGQVL DSRSQSPWRL SLITDFFWGI AEFVVLFFK ${ }^{39} \mathrm{~T}$ LLQQDVK $K^{47} K^{48} \mathrm{RR}$ 051 SYGNṠุSDSRY DDGRGPPGNP PRRMG̣ंRINHL RGPSPPPMAG GUGR

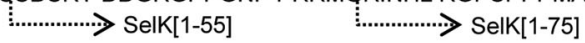

b

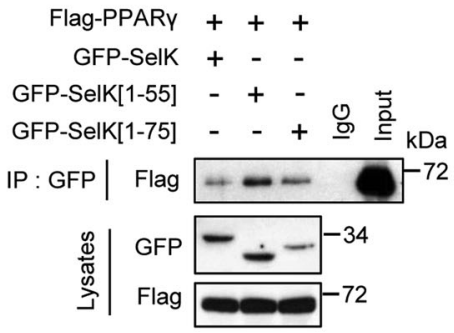

d

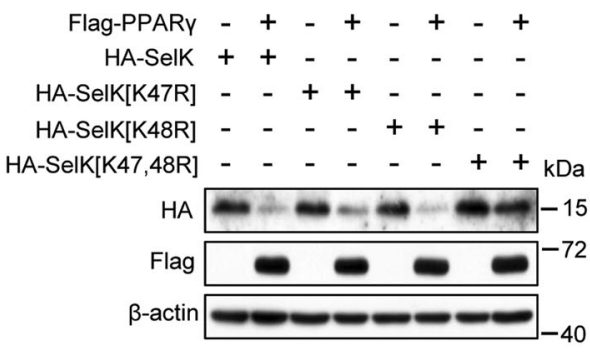

C

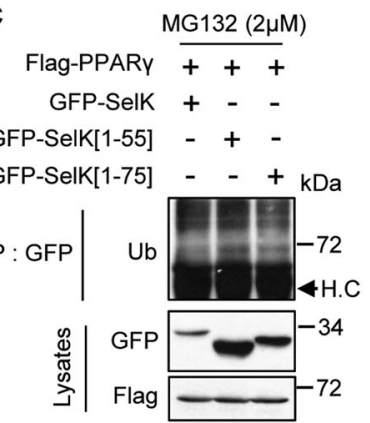

e

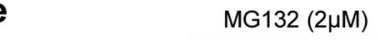

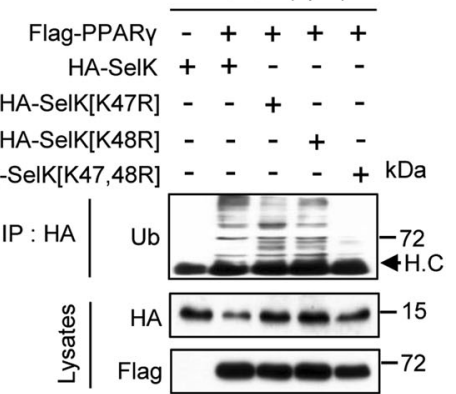

Fig. 7 Both $\mathrm{Lys}^{47}$ and $\mathrm{Lys}^{48}$ of SelK are required for PPAR $\gamma$-mediated ubiquitination. a Amino acid sequence of SelK is represented. The following elements of residues and domains are marked: italic letters (Lys residues), under lined letters (TM region). The construction of SelK mutants, GFP-SelK[1-55] and GFP-SelK[1-75] has been described in the Materials and methods section. b MCF7 cells were cotransfected with Flag-PPAR $\gamma$ and GFP-SelK or the truncation mutants of SelK for $48 \mathrm{~h}$. Lysates and immunoprecipitation samples (anti-GFP and anti-IgG) were analyzed using the indicated antibodies. Cell lysates (5\% input) were used as positive control. c Transfected MCF7

PPAR $\gamma$. To do this, we constructed two truncation mutants of GFP-SelK as shown in Fig. 7a. Both SelK truncation mutants interacted with Flag-PPAR $\gamma$ (Fig. 7b) and were ubiquitinated in MCF7 cells transfected with Flag-PPAR $\gamma$ (Fig. 7c). These data suggest that a region in the $\mathrm{N}$-terminal 55 amino acids of SelK is required for interaction with PPAR $\gamma$, and that Lys residues at 47 th or 48th positions in the cytosolic tail of SelK may be the putative ubiquitination site. To identify the specific site for ubiquitination of SelK, each Lys residue was mutated into Arg. Like wild-type SelK, both the mutants, HA-SelK[K47R] and HA-SelK [K48R], were ubiquitinated and degraded by Flag-PPAR $\gamma$. However, Flag-PPAR $\gamma$-mediated ubiquitination and degradation of HA-SelK[K47, 48R] in which both Lys residues were mutated into Arg were significantly decreased (Fig. 7d, e). These data suggest that both $\mathrm{Lys}^{47}$ and Lys ${ }^{48}$ of SelK are poly-ubiquitinated by PPAR $\gamma$, and this ubiquitination is required for protein degradation. cells, under same conditions as (b), were treated with $2 \mu \mathrm{M} \mathrm{MG132}$ for $12 \mathrm{~h}$. Lysates and immunoprecipitation samples (anti-GFP) were analyzed by western blotting with the indicated antibodies. d MCF7 cells were co-transfected with Flag-PPAR $\gamma$ and HA-SelK or Lys-toArg mutants of SelK for $48 \mathrm{~h}$. Whole cell lysates were analyzed by western blotting using indicated antibodies. e Transfected MCF7 cells, under same conditions as (d), were treated with $2 \mu \mathrm{M}$ MG132 for $12 \mathrm{~h}$. Lysates and immunoprecipitation samples (anti-HA) were analyzed by western blotting with the indicated antibodies. HC heavy chain, IP immunoprecipitation

\section{PPARY-mediated ubiquitination and degradation of both SelS and SelK are required for 3T3-L1 differentiation}

The effect of ubiquitination and degradation of the selenoproteins induced by PPAR $\gamma$ on adipogenesis was examined using 3T3-L1 pre-adipocytes transfected with siPPAR $\gamma$ or control siRNA. Compared to control cells, protein levels of both SelS and SelK in PPAR $\gamma$ knockdown 3T3-L1 cells were high, whereas intracellular lipid accumulation was very low (Fig. 8a, b). We also found that mRNA levels of SelS and SelK were unchanged in siPPAR $\gamma$-transfected 3T3-L1 cells, but those of adipogenesis- and lipid synthesisrelated genes encoding PPAR $\gamma$ and fatty acid synthase were decreased (Fig. 8c). These results indicate that PPAR $\gamma$ is an essential protein for adipocyte differentiation, as previously reported [34], and that it has the ability to degrade both SelS and SelK proteins during adipogenesis. To further 
a

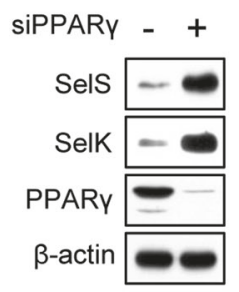

b

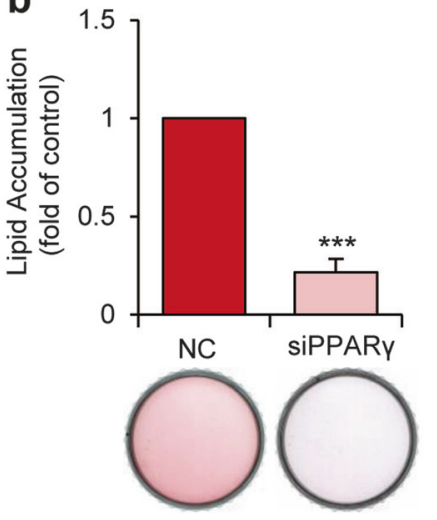

C

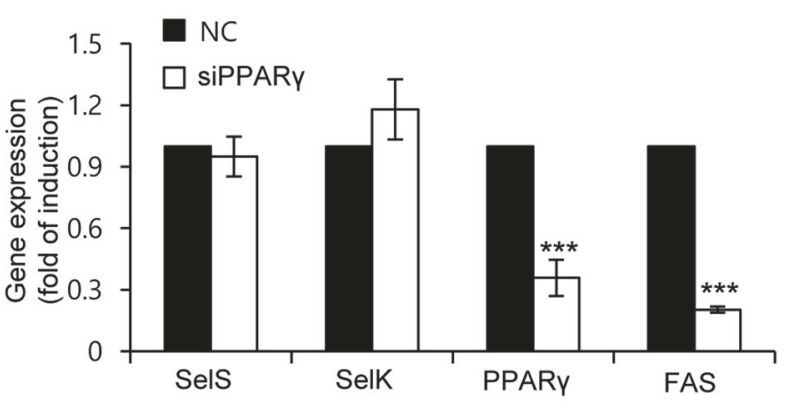

d
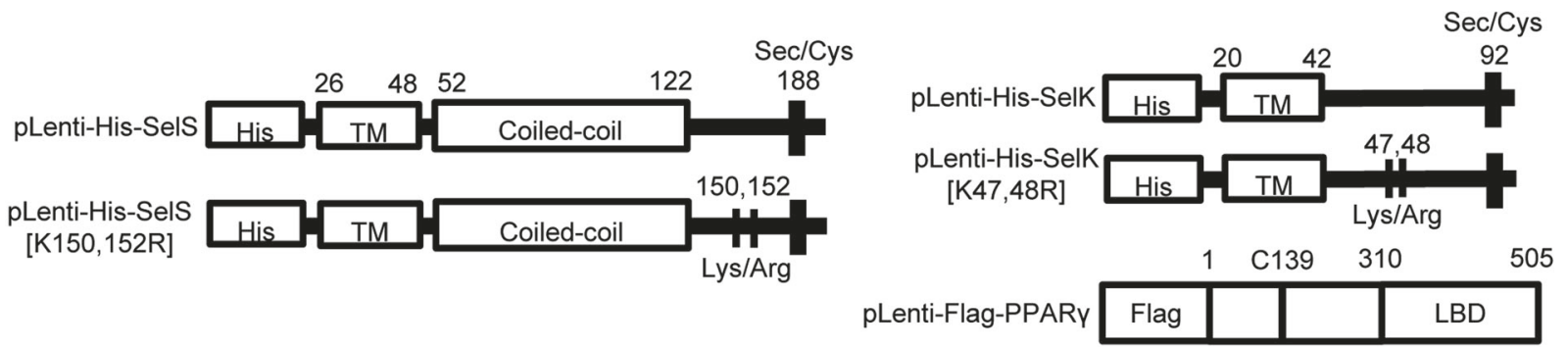

e

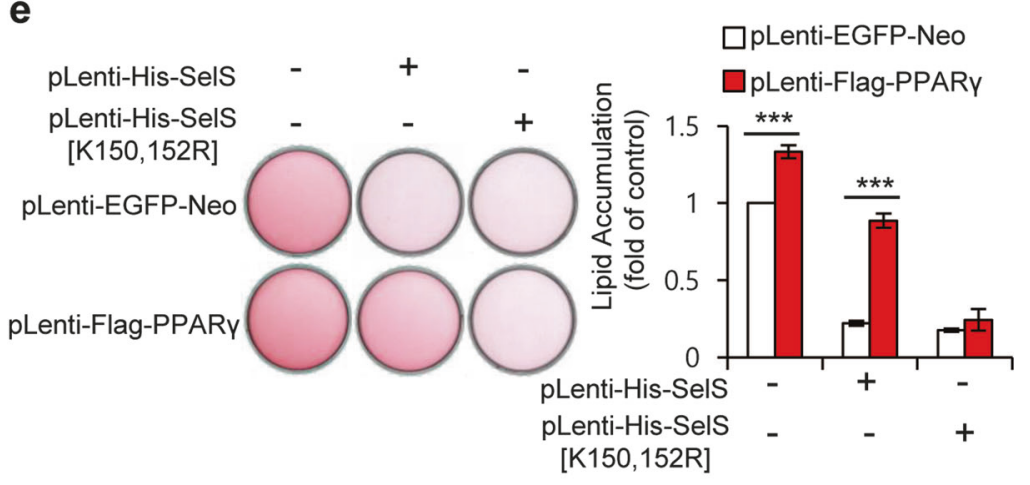

g

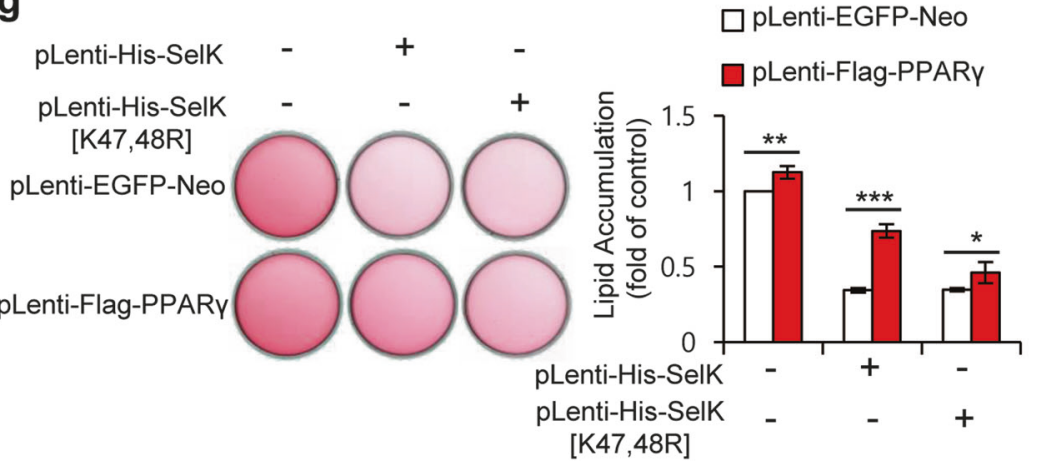

f

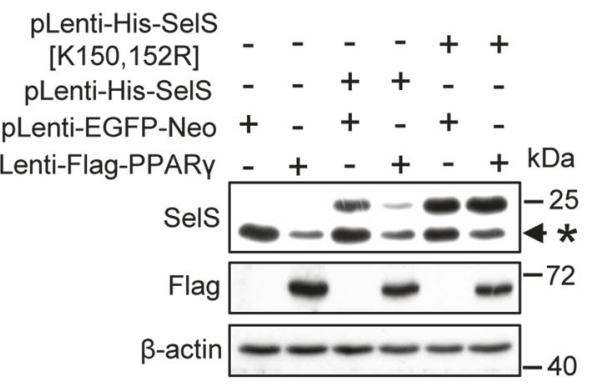

h
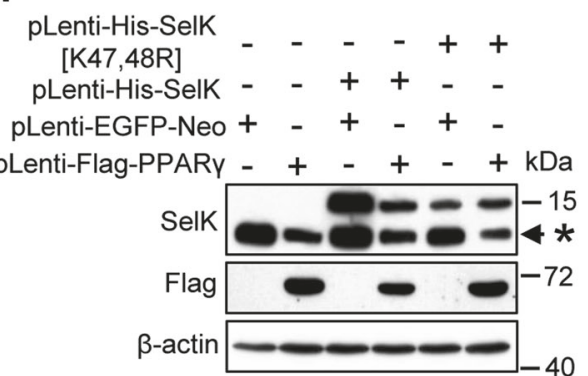

investigate the effect of PPAR $\gamma$-mediated SelS and SelK degradation on adipocyte differentiation, we constructed lentivirus plasmids (Fig. 8d). Compared to control cells, intracellular lipid accumulation in His-SelS- or His-SelS [K150, 152R]- overexpressing cells was decreased. The intracellular lipid accumulation was restored by lentivirusmediated Flag-PPAR $\gamma$ expression in pLenti-His-SelS- transduced cells but not in His-SelS[K150, 152R]-overexpressing cells (Fig. 8e and Supplementary fig. S2a). Protein levels of both endogenous SelS and overexpressed His-SelS were decreased by expression of Flag-PPAR $\gamma$ during adipocyte differentiation. However, the level of His-SelS[K150, 152R] protein was not decreased by expression of Flag-PPAR $\gamma$ (Fig. 8f). And, both pLenti-His- 
Fig. 8 PPAR $\gamma$-mediated degradation of both SelS and SelK is essentially required for 3T3-L1 differentiation. a 3T3-L1 cells were transfected with siPPAR $\gamma$ or control siRNA. These pre-adipocytes were differentiated for 2 days. Whole cell lysates were analyzed by western blotting using indicated antibodies. b 3T3-L1 cells were transfected with siPPAR $\gamma$ or control siRNA. These pre-adipocytes were differentiated for 6 days, and then cells were fixed. Intracellular lipid droplets in differentiated adipocytes were stained with ORO for image analysis (bottom panel). Quantification of lipid accumulation in the ORO-stained lipid droplets was performed as described in the Materials and methods section (upper panel). c The cells differentiated under same conditions as (b) were also harvested at day 6 for analyzing the mRNA levels of PPAR $\gamma$, SelS, SelK, and fatty acid synthase by quantitative RT-PCR. $\beta$-actin was used for normalization. FAS fatty acid synthase. d Organization of cloned lentiviral plasmids is schematically represented. e, f 3T3-L1 pre-adipocytes were co-transduced with lentivirus-containing control vector (pLenti-EGFP-neo) or FlagPPAR $\gamma$ (pLenti-Flag-PPAR $\gamma$ ), and His-SelS (pLenti-His-SelS) or HisSelS[K150, 152R] (pLenti-His-SelS[K150, 152R]). g, h 3T3-L1 preadipocytes were co-transduced with lentivirus-containing control vector (pLenti-EGFP-neo) or Flag-PPAR $\gamma$ (pLenti-Flag-PPAR $\gamma$ ), and His-SelK (pLenti-His-SelK) or His-SelK[K47, 48R] (pLenti-His-SelK $[\mathrm{K} 47,48 \mathrm{R}])$. These cells were differentiated for $2(\mathbf{f}, \mathbf{h})$ or $6(\mathbf{e}, \mathbf{g})$ days. $\mathbf{e}, \mathbf{g}$ Intracellular lipid droplets in differentiated adipocytes were stained with ORO for image analysis (left panels). Quantification of lipid accumulation in the ORO-stained lipid droplets was performed as described in the Materials and methods section (right panels). f, h Whole cell lysates were analyzed by western blotting using indicated antibodies. Asterisk (*) indicates endogenous SelS (f) or SelK (h). All graphs indicate the results from three independent experiments. The error bars represent \pm S.D., and the $p$-values represent comparisons with each control $\left(* * * p<0.001 * * p<0.005,{ }^{*} p<0.05\right)$

SelK- and pLenti-His-SelK[K47, 48R]-transduced cells showed decreased intracellular lipid accumulation. When Flag-PPAR $\gamma$ was expressed, the decreased intracellular lipid accumulation was recovered more in lentivirus-mediated His-SelK-overexpressing cells than in His-SelK[K47, 48R]overexpressing cells (Fig. 8g and Supplementary fig. S2b). Endogenous SelK and overexpressed His-SelK were decreased by expression of Flag-PPAR $\gamma$. However, this decrease did not occur in pLenti-His-SelK[K47, 48R]transduced cells (Fig. 8h). We also observed that mRNA levels of PPAR $\gamma$ were decreased in 3T3-L1 cells overexpressing His-SelS or His-SelK during adipogenesis, as well as adiponectin which is a lipid synthesis marker (Supplementary fig. S2c and d). These results suggest that accumulation of either SelS or SelK inhibits adipocyte differentiation, and PPAR $\gamma$-mediated degradation of SelS and SelK is an essential requirement for adipocyte differentiation.

\section{Discussion}

It has been reported that some selenoproteins, such as selenoprotein $\mathrm{W}$, selenoprotein $\mathrm{P}$, and selenoprotein $\mathrm{O}$ have a function in various cellular processes, such as myogenesis [35, 36], bone remodeling and adipogenesis [37, 38], chondrogenesis [39]. It has also been shown that some selenoproteins have a function in maintaining cellular redox homeostasis [24]. In this study, we investigated the function of two selenoproteins localized on the ER membrane, SelS and SelK, in adipogenesis. These selenoproteins contain a single TM domain and a C-terminal end that faces the cytosol (Fig. 3b). The cytosolic tails of the proteins are highly unstructured. Both SelS and SelK are involved in ER stress signaling through p97/VCP-dependent ERAD, and proline residues in the C-terminal region of SelS or SelK are essential for their interaction with p97/VCP [21, 22, 29]. ER stress promotes adipocyte differentiation and development of obesity [18, 20, 23]. A recent study suggested that SelS might play an inhibitory role in adipogenesis [18]. However, the inhibitory mechanism of SelS is still unknown, and the role of SelK in adipogenesis has not been studied at all. In this study, we found that the protein expression of both SelS and SelK was inversely proportional to that of PPAR $\gamma$ (Fig. 1h). We also found that overexpression of SelS or SelK in pre-adipocytes resulted in impaired adipogenesis (Fig. 8e, g, and Supplementary fig. S2c and d). These results imply that SelS and SelK are novel proteins that may play a role in inhibiting adipocyte differentiation. Both SelS and SelK are known as negative regulators of the ER stress signaling pathway [22]. It has been demonstrated that expression of ER stress-related selenoproteins plays a critical role in the expression of XBP1 [21, 26], which is an ER stress-induced transcription factor required for initiation of the early phase of adipogenesis $[23,40]$. Transcription of PPAR $\gamma$ is regulated by ER stress-inducible spliced XBP1, which stimulates adipogenesis by up-regulating PPAR $\gamma$ expression [23]. Therefore, it would be plausible to assume that the anti-adipogenesis functions of SelS and SelK are likely to act through modulation of ER stress and UPR during adipocyte differentiation.

PPAR $\gamma$ is the master regulator of adipogenesis and is abundantly expressed in adipose tissue. Two isoforms of PPAR $\gamma$ have been identified, PPAR $\gamma 1$ and PPAR $\gamma 2$, which are generated by alternative splicing and differential promoter usage. Expression of PPAR $\gamma 2$ is specific to adipose tissue, whereas PPAR $\gamma 1$ is expressed in many tissues such as intestinal tract, liver, lung, and the immune system under physiological conditions [14, 41-43]. Expression of PPAR $\gamma$ is controlled at the transcriptional and post-translational levels [5, 44]. PPAR $\gamma$ is a short-lived protein, which is controlled by post-translational modifications. It has been reported that PPAR $\gamma$ is poly-ubiquitinated and degraded in a proteasome-dependent manner [13, 45]. Moreover, it has also been reported that PPAR $\gamma$ functions as an E3 ligase to induce ubiquitination of substrates, which is independent of its transcriptional activity $[15,16]$. In this study, we first report that PPAR $\gamma$ functions as an E3 ligase to degrade SelS and SelK through poly-ubiquitination at Lys ${ }^{150}$ and Lys ${ }^{47} /$ 
Lys $^{48}$, respectively (Figs. 5, 6, 7). We also found that ubiquitination and degradation of both SelS and SelK through the E3 ligase activity of PPAR $\gamma$ are independent of its activation by ligand (Supplementary fig. S1), and are required for adipocyte differentiation (Fig. 8). It has been known that Lys48-linked poly-ubiquitination are the most abundant in cells $[46,47]$ and thought to be the major signal for proteasome-mediated degradation $[48,49]$. PPAR $\gamma$ also induced Lys-48-linked ubiquitination and degradation of p65 [15]. It has been reported that E3 enzymes regulate conjugate type of their substrates specifically [50]. Therefore, it is presumed that the Lys48-linked poly-ubiquitination of SelS and SelK may be induced by PPAR $\gamma$ during adipogenesis.

Recently, SelS has been suggested to be involved in neurodegenerative disorders, such as Alzheimer disease, by regulating ER stress [27]. It has also been shown that SelK regulates $\mathrm{Ca}^{2+}$ flux during immune responses [51]. In this study, we report a new function of SelS and SelK in inhibiting adipogenesis, and suggest that these two ER-resident selenoproteins are potential novel therapeutic targets for obesity (Fig. 8e, g). It has been reported that obesity is linked to cancer [52]. Using the leptin-deficient (ob/ob) mouse which is the model of type 2 diabetes with obesity [53], we observed the protein level of PPAR $\gamma$ was significantly increased in liver of $o b / o b$ mice compared to wild type, whereas those of both SelS and SelK were decreased (Supplementary fig. 3a). To understand the effect of SelS and SelK expression on human cancer, we performed Kaplan-Meier survival analysis based upon data generated by the Gene Expression Omnibus on an online platform [54, 55]. The results showed that lower expression of SelS or SelK was associated with the poor prognosis of gastric cancer patients (supplementary Fig. S3b, c).

While we report for the first time the degradation of SelS and SelK by E3 ligase activity of PPAR $\gamma$ during adipogenesis, the inhibitory mechanism of SelS and SelK during adipogenesis still remains obscure. Further studies on the inhibitory mechanism of SelS and SelK during adipogenesis may provide meaningful candidates for therapeutic intervention in obesity.

\section{Materials and methods}

\section{Cell culture and adipocyte differentiation}

The human colon cancer cell line (HT29) and human breast adenocarcinoma cell line (MCF7) were cultured in RPMI containing $10 \%$ fetal bovine serum (FBS, Hyclone, GE healthcare Life Sciences, UT, USA) at $37^{\circ} \mathrm{C}$ in a humidified $5 \% \mathrm{CO}_{2}$ atmosphere. Adipocytes were differentiated from pre-adipocytes (3T3-L1) [18]. 3T3-L1 cells were cultured in Dulbecco's modified Eagle's medium (DMEM) with $10 \%$ fetal calf serum (Gibco, Invitrogen, Carlsbad, CA, USA) at $37^{\circ} \mathrm{C}$ in a humidified $5 \% \mathrm{CO}_{2}$ atmosphere. At day 0 , when $3 \mathrm{~T} 3$-L1 pre-adipocytes were at two-days postconfluence, differentiation was induced with DMEM containing 10\% FBS, $2 \mu \mathrm{g} / \mathrm{mL}$ insulin (Sigma-Aldrich, St. Louis, MO, USA), $115 \mu \mathrm{g} / \mathrm{mL}$ 3-isobutyl-1methylxanthine (IBMX, Sigma-Aldrich) and $5 \mu \mathrm{M}$ Dex (Sigma-Aldrich) for 2 days. Medium was then changed to DMEM containing $10 \%$ FBS and $2 \mu \mathrm{g} / \mathrm{mL}$ insulin (Sigma-Aldrich), and incubated for 2 additional days. The cells were then cultured in DMEM with 10\% FBS until indicated days. For liganddependent activation of PPAR $\gamma$, rosiglitazone (SigmaAldrich) was treated to 3T3-L1 or HT29 or MCF7 cells for $24 \mathrm{~h}$.

\section{Oil red 0 staining}

To determine the intracellular lipid accumulation in differentiated 3T3-L1 cells, ORO staining was performed according to the method described by Kim et al. [18], with a slight modification. Adipocytes were fixed with $4 \%$ paraformaldehyde for $24 \mathrm{~h}$ at $24^{\circ} \mathrm{C}$ and then incubated with fresh ORO solution (Sigma-Aldrich) for $15 \mathrm{~min}$. The OROstained cells were scanned using EPSON PERPECTION 3200 scanner. Quantification of ORO-stained intracellular lipid was done by measuring the optical density of isopropanol-extracted ORO dye from ORO-stained cells at $500 \mathrm{~nm}$.

\section{Isolation of RNA, RT-PCR, and real-time RT-PCR}

Total RNA was extracted from the cells with TRIzol (Invitrogen) according to the manufacturer's instructions. Reverse transcription was performed to generate cDNA using $1 \mu \mathrm{g}$ of isolated RNA and a SuperScript III reverse transcriptase kit (Invitrogen). RT-PCR analysis of the resulting cDNA preparation was performed using PCR Premix, Sapphire (Super Bio Co., Seoul, Korea) [56]. The PCR products were loaded on $2 \%$ agarose gels and visualized by ethidium bromide staining. Real-time RT-PCR analysis of the resulting cDNA preparation was performed using the LightCycler 480 SYBR Green I Master (Roche Diagnostics, Manheim, Germany) [36]. The sequences of primers used in RT-PCR and real-time RT-PCR were as follows (forward and reverse, respectively): mouse SelS, 5' GAG GCT TTA GCA GCT GCT CG-3', 5'-GTC AGA GGG TTA TAA CCA CCT CC-3'; human SelS, 5'-GAA GAA CTA AAT GCG CAA GTT G- $3^{\prime}$ and $5^{\prime}$-GCG TCC AGG TCT CCA GGA GCA AGC-3'; mouse SelK, 5'-GTT TAC ATC TCG AAT GGT CAG G-3' and 5'-CC ACC AGC CAT TGG AGG AGG GC-3'; human SelK, 5'-GTT TAC ATC TCG AAC GGA CAA G-3' and 5'-CC ACC 
AGC CAT TGG AGG GGG AC-3'; mouse PPAR $\gamma, 5^{\prime}-$ CCC AAT GGT TGC TGA TTA CAA AT-3' and 5'-CTA CTT TGA TCG CAC TTT GGT ATT CT-3'; human PPAR $\gamma, 5^{\prime}-$ GGG TGA AAC TCT GGG AGA TTC-3' and $5^{\prime}$-CT TGT GAA TGG AAT GTC TTC-3'; mouse C/EBP $\alpha$, 5'-CCC ACT TGC AGT TCC AGA T-3' and 5'-CTG TTC TTG TCC ACC GAC TT-3'; mouse GRP78; 5'-CGG ACG CAC TTG GAA TGA C-3' and 5'-AAC CAC CTT GAA TGG CAA GAA-3'; mouse spliced-XBP1; 5'-CTG AGT CCG CAG CAG GT-3' and 5'-TGT CAG AGT CCA TGG GAA GA-3'; mouse adiponectin, 5'-GAT GCA GGT CTC TTG GTC CTA A-3' and 5'-GGC CCT TCA GCT CCT GTC A-3'; mouse fatty acid synthase, 5'-GGC CCC TCT GTT AAT TGG CT-3' and 5'-GGA TCT CAG GGT TGG GGT TG-3'; human glyceraldehyde-3-phosphate dehydrogenase (GAPDH), 5'-CTG CAC CAC CAA CTG CTT AGC-3' and 5'-CTT CAC CAC CTT CTT GAT GTC-3'; mouse $\beta$-actin, $5^{\prime}$-ATG CCC TGA GGC TCT TTT CC-3' and 5'-TGC TAG GAG CCA GAG CAG TC-3'. The realtime RT-PCR data were normalized to mouse $\beta$-actin.

\section{Antibodies and immunoblot analysis}

The cells were lysed as described in our previous study [57]. Immunoblot analysis was performed as described previously [21]. Antibodies were obtained from the following sources: the anti-His and anti-HA antibodies were from Applied Biological Materials (ABM, Richmond, BC, Canada), the anti-Flag and anti-SelK antibodies were obtained from Sigma-Aldrich, the anti-PPAR $\gamma$ antibody was obtained from Cell Signaling Technology (Danvers, MA, USA), and the anti-GST, anti-Ub, anti- $\beta$-actin, and antiGRP78 antibodies were obtained from Santa Cruz Biotechnology (Santa Cruz, CA, USA). The anti-SelS antibody was prepared as described previously [21].

\section{Cycloheximide chase assay}

To determine the degree of SelS, SelK, His-SelS, and HASelK degradation, CHX chase analysis was performed according to the method described by Ballar et al. [58], with slight modification. CHX was purchased form SigmaAldrich.

\section{Construction of SelS, SelK and PPARy mutants}

The human PPAR $\gamma 2$ plasmid, Flag-PPAR $\gamma$ was a gift from Dr. Jesang Ko (Korea University) [59]. Point mutations in Flag-PPAR $\gamma$ at $\mathrm{Cys}^{139}$ to Ala (Flag-C139A) and truncation mutations in Flag-PPAR $\gamma$ and Flag-C139A at their LBD were generated by site-directed mutagenesis reactions using QuikChange site-directed mutagenesis kit according to the instructions of the manufacturer (Stratagene, CA, USA).
These plasmids were named Flag-PPAR $\gamma(\Delta \mathrm{LBD})$ and FlagC139A( $\Delta$ LBD), respectively. The human SelS plasmid HisSelS (Sec ${ }^{188}$ changed to Cys) and the human SelK plasmid HA-TEV-SelK, named HA-SelK, were constructed as described previously [21, 22]. His-SelS was then used as a template DNA for the following SelS mutants. His-SelS [1-122], His-SelS[1-144], and His-SelS[1-167] were constructed as described previously [21]. Point mutation in HisSelS at Lys ${ }^{150}$, Lys ${ }^{152}$, Lys ${ }^{156}$, and double point mutation at Lys ${ }^{150}$ with Lys ${ }^{152}$ to Arg were generated by site-directed mutagenesis reactions using QuikChange site-directed mutagenesis kit according to the manufacturer's instructions (Stratagene). These plasmids were named His-SelS [K150R], His-SelS[K152R], His-SelS[K156R], and HisSelS[K150,152R], respectively. Lys residues, positioned at 47th, 48th, and both 47th and 48th in HA-SelK, were changed to Arg following QuikChange site-directed mutagenesis protocol (Stratagene). These plasmids were named HA-SelK[K47R], HA-SelK[K48R], and HA-SelK [K47,48R], respectively. The human SelK plasmid GFPSelK, named GFP-SelK, was constructed as described previously [22]. This plasmid was then used as a template DNA for following truncation mutants. The primers used for constructing plasmids that were designed for GFP-SelK [1-55] and GFP-SelK(1-55) were as follows: GFP-SelK [1-55] forward, 5'-GC TAT GGA AAC TCA TAA GTC GAC CCG GGC GGC CGC TTT CAT-3' and reverse, 5'CGG GTC GAC TTA TGA GTT TCC ATA GCT TCT TCT TTT TTT CAC-3'; GFP-SelK[1-75] forward, 5'-CGA AGA ATG GGT TAA GTC GAC CCG GGC GGC CGC TTT CAT-3' and reverse, 5'-CGG GTC GAC TTA ACC CAT TCT TCG GGG AGG GTT TCC TGG-3'. All SelS, SelK and PPAR $\gamma$ mutants were confirmed by sequencing (Macrogen, Seoul, Korea).

\section{Construction and purification of the GST fusion SelS and SelK mutants}

Deletion mutations in His-SelS at the TM domain (amino acids from 26th to 48th), and in HA-SelK at the TM domain (amino acids from 20th to 42nd) and at $\mathrm{Sec}^{92}$ changed to Cys were generated by site-directed mutagenesis reactions using QuikChange site-directed mutagenesis kit according to the manufacturer's instructions (Stratagene). TM regions and hydrophobic domains are deleted from His-SelS and HA-SelK to allow the production and purification of GST fusion proteins [60]. These TM-deleted plasmids were used as templates for GST fusion SelS and SelK. The primers used for constructing plasmids that were designed for GST$\operatorname{SelS}(\Delta \mathrm{TM})$ and GST-SelK $(\Delta \mathrm{TM})$ were as follows: GST$\operatorname{SelS}(\Delta \mathrm{TM})$ forward, 5'-GC GGA TCC ATG GAA CGC CAA GAG GAG TCT CTG-3' and reverse, 5'-CG CTC GAG TTA GCC GCA TCC GCC AGA TGA CGG-3'; 
GST-SelK $(\Delta \mathrm{TM})$ forward, 5'-GC GGA TCC ATG GTT TAC ATC TCG AAC GG $-3^{\prime}$ and reverse, $5^{\prime}$-GC CTC GAG TTA CCT TCC GCA TCC ACC AGC C-3'. The PCR products were cloned into the BamHI and XhoI sites of pGEX-4T-3 vector. These plasmids were designated GST-SelS $(\Delta \mathrm{TM})$ and GST-SelK $(\Delta \mathrm{TM})$. The plasmids were confirmed by sequencing (Macrogen). The GST, GST-SelS $(\Delta \mathrm{TM})$, and GST-SelK $(\Delta \mathrm{TM})$ proteins were expressed in $E$. coli with $1 \mathrm{mM}$ isopropyl 1 -thio- $\beta$-D-galactopyranoside induction for $6 \mathrm{~h}$ at $18{ }^{\circ} \mathrm{C}$. The protein was lysed by sonication. The lysis buffer contained $50 \mathrm{mM}$ Tris- $\mathrm{HCl}(\mathrm{pH}$ 8.0), $120 \mathrm{mM} \mathrm{NaCl}, 0.5 \%$ Nonidet P- $40,4 \mu \mathrm{g} / \mathrm{mL}$ leupeptin, and $1 \mathrm{mM}$ PMSF. The prepared cell lysates were incubated with glutathione beads (Invitrogen) for $2 \mathrm{~h}$ at $4{ }^{\circ} \mathrm{C}$. The GST beads were washed with wash buffer containing $20 \mathrm{mM}$ Tris- $\mathrm{HCl}$ (pH 8.0), $100 \mathrm{mM} \mathrm{NaCl}, 1 \mathrm{mM}$ EDTA, $0.05 \%$ sodium dodecyl sulfate (SDS), and $0.5 \%$ Nonidet P-40 and then eluted with elution buffer containing $50 \mathrm{mM}$ Tris- $\mathrm{HCl}$ (pH 8.0), $20 \mathrm{mM} \mathrm{KCl}, 1 \mathrm{mM}$ DTT, and $20 \mathrm{mM}$ glutathione for $10 \mathrm{~min}$ at $37^{\circ} \mathrm{C}$.

\section{RNA interference}

The siPPAR $\gamma$ used in this study was obtained by Ambion (Thermo Fisher Scientific, Waltham, MA, USA; Catalog number: \#AM51331). The siPPAR $\gamma$ was a validated siRNA for human (NM_005037) and mouse (NM_011146) PPAR $\gamma$. The sequence for siPPAR $\gamma$ was as follows: sense, 5'-GGG CGA UCU UGA CAG GAA Att-3' and anti-sense, 5'-UUU CCU GUC AAG AUC GCC Ctc-3'. A stealth negative control siRNA was obtained from Invitrogen. HT29 and 3T3-L1 cells were transfected with siRNAs using a microporator (Neon Transfection System, Invitrogen).

\section{Transfection}

For transfection, $3 \times 10^{5} \mathrm{MCF} 7$ cells were seeded in $60 \mathrm{~mm}$ dishes. At $16 \mathrm{~h}$ after seeding, these cells were transfected with plasmids using Lipofectamine 2000 transfection reagent (Invitrogen) according to the manufacturer's instructions [21, 22].

\section{Immunoprecipitation and ubiquitin assay}

For immunoprecipitation, cells were transfected with siRNA or plasmids. To detect poly-ubiquitination, these cells were treated with $2 \mu \mathrm{M}$ MG132 for $12 \mathrm{~h}$ before harvest. The lysates were mixed with antibodies for $16 \mathrm{~h}$ at $4{ }^{\circ} \mathrm{C}$. Immune complexes were incubated with protein Gagarose for $90 \mathrm{~min}$ at $4{ }^{\circ} \mathrm{C}$, then washed with lysis buffer three times, and boiled with SDS sample buffer for $5 \mathrm{~min}$ $[21,36]$. The samples were loaded onto SDSpolyacrylamide gels and subjected to electrophoresis, transferred to polyvinylidene fluoride membranes, and incubated with primary antibody for $16 \mathrm{~h}$ at $4{ }^{\circ} \mathrm{C}$. After further incubation with a horseradish peroxidase-conjugated secondary antibody for $1 \mathrm{~h}$ at room temperature, immunoreactive bands were visualized using a West Pico enhanced ECL detection kit (Thermo Fisher Scientific).

\section{GST pull-down assay}

MCF7 cells were transfected with Flag-PPAR $\gamma \mathrm{s}$ in $60 \mathrm{~mm}$ dishes. The cells were lysed with lysis buffer [22]. After the purification of GST, GST-SelS( $\Delta \mathrm{TM})$, and GST-SelK $(\Delta \mathrm{TM})$ proteins as described above, the purified GST proteins were pre-incubated with the cell lysates and rotated for $16 \mathrm{~h}$ at $4^{\circ}$ C. Glutathione beads were added to the mixtures and rotated for an additional $30 \mathrm{~min}$ at room temperature. The beads were washed and then eluted. The eluted products were visualized using Coomassie Blue staining or western blotting.

\section{In vitro ubiquitin assay}

For poly-ubiquitination formation assay, MCF7 or HT29 cells were transfected with Flag-PPAR $\gamma$ or siPPAR $\gamma$ in $60 \mathrm{~mm}$ dishes. The cells were lysed with lysis buffer. After the purification of GST, GST-SelS( $\Delta \mathrm{TM})$, and GST-SelK $(\Delta \mathrm{TM})$ proteins as described above, the cell lysates and purified proteins were incubated in reaction buffer $[50 \mathrm{mM}$ $\mathrm{NaCl}, 0.5 \mathrm{mM}$ dithiotheritol, and $40 \mathrm{mM}$ Tris-HCl (pH 7.4)] using Amicon Ultra Centrifugal filler device (Amicon Ultra0.5, Millipore, MA, USA). GST fusion proteins were incubated with $2 \mathrm{mM}$ ATP (Fermantas, Vilnius, Lithuania, R0441) and $5 \mu \mathrm{M}$ Ubiquitin (Sigma-Aldrich, U6235) in transfected cell lysates in $500 \mu \mathrm{L}$ of reaction buffer for $3 \mathrm{~h}$ at $37^{\circ} \mathrm{C}$. After incubation, reaction mixtures were boiled in $0.5 \%$ SDS to disrupt any protein interactions [13] and then glutathione beads were added to the reaction mixtures, which were then rotated for an additional $30 \mathrm{~min}$ at $24^{\circ} \mathrm{C}$. The beads were washed and then eluted. The eluted products were visualized using western blotting.

\section{Construction of lentiviral plasmids, production of lentivirus, and transduction}

His-SelS and His-SelS[K150, 152R] plasmids were changed from Sec ${ }^{188}$ to Cys. His-SelK and His-SelK[K47, 48R] plasmids were changed from $\mathrm{Sec}^{92}$ to Cys, and were constructed as described previously [21]. Flag-PPAR $\gamma$ was constructed as described above. These plasmids were used as templates for constructing the lentiviral vector (pLentiEGFP-neo; Clontech, Takara Bio, CA, USA). The GFP expression region in pLenti-EGFP-neo vector was replaced to His-SelSs or His-SelKs or Flag-PPAR $\gamma$ using XbaI and SalI sites. The primers for these lentiviral plasmids were as 
follows (forward and reverse, respectively): His-SelSs (HisSelS, His-SelS[K150, 152R]), 5'-GCT CTA GAG ATG GGG GGT TCT CAT CAT CAT CAT CAT CAT GG-3' and 5'-GC GTC GAC TTA GCC GCA TCC GCC AGA TGA CGG GCC TCT GCG-3'; His-SelKs (His-SelK, HisSelK[K47, 48R]), 5'-GCT CTA GAG ATG GGG GGT TCT CAT CAT CAT CAT CAT CAT GG-3' and 5'-GC GTC GAC TTA CCT TCC GCA TCC ACC AGC CAT TGG AGG GGG-3'; Flag- PPAR $\gamma$, 5'-GCT CTA GAG ATG GAT TAC AAG GAT GAC GAC GAT AAG G-3' and 5'-GC GTC GAC CTA ATA CAA GTC CTT GTA GAT CTC CTG G-3'. The PCR products were cloned into the XbaI and SalI sites of pLenti-EGFP-neo. These plasmids were designated pLenti-His-SelS, pLenti-His-SelS [K150,152R], pLenti-His-SelK, pLenti-His-SelK [K47,48R], and pLenti-Flag-PPAR $\gamma$, respectively. The cloned-pLenti-viral vectors or pLenti-EGFP-neo were transfected into HEK293T cells with pCMV-VSV-G and $\Delta 8.9$ (Clontech) using Lipofectamine 2000 transfection reagent (Invitrogen). The viruses were harvested every $24 \mathrm{~h}$ from 24 to $72 \mathrm{~h}$ post-transfection with cell culture medium. The viruses in the culture supernatants were precipitated overnight with $10 \%$ poly(ethylene glycol) 8000 (SigmaAldrich) and $0.4 \mathrm{M} \mathrm{NaCl}$ and then centrifuged at $10,000 \times g$ for $10 \mathrm{~min}$ [61]. The 3T3-L1 cells were transduced with these lentiviruses in DMEM-containing $10 \%$ fetal calf serum (Gibco, Invitrogen) and $8 \mu \mathrm{g} / \mathrm{mL}$ of polybrene (Sigma-Aldrich) for $24 \mathrm{~h}$, and then the cells were differentiated for indicated days.

\section{Animal tissues}

Liver tissues of wild-type and $o b / o b$ mice were kindly provided by Dr. Seung-Hoi Koo (Korea University). The liver tissues were lysed, and then subjected to immunoblot analysis [21].

\section{Online gastric cancer tissue database and data retrieval}

Overall survival of gastric cancer patients was analyzed using the online mRNA expression database developed by Gyorffy B (http://kmplot.com) [54]. The data were retrieved from the gene expression omnibus (GEO). The two patient cohorts were compared by a Kaplan-Meier survival plot, and the hazard ratio with $95 \%$ confidence intervals and $\log$ rank $p$ value were calculated. $p$-Values $<0.05$ were considered significant.

\section{Data analysis and statistics}

All data in this study are represented as the means and standard deviations of the control value. Statistical comparisons from at least three independent experiments were determined using Student's $t$-tests. $p$-Values $<0.05$ were considered significant.

Acknowledgements This work was supported by the National Research Foundation of Korea (NRF) grant funded by the Korea government (MSIP) (NRF-2016R1A2B4009525). We also acknowledge the valuable help provided by Prof. Byung-Yoon Ahn, Prof. Jesang Ko, Prof. Seung-Hoi Koo, and Mr. Gi Uk Jeong of Korea University.

\section{Compliance with ethical standards}

Conflict of interest The authors declare that they have no conflict of interest.

\section{References}

1. Barness LA, Opitz JM, Gilbert-Barness E. Obesity: genetic, molecular, and environmental aspects. Am J Med Genet A. 2007;143A:3016-34.

2. de Ferranti S, Mozaffarian D. The perfect storm: obesity, adipocyte dysfunction, and metabolic consequences. Clin Chem. 2008;54:945-55.

3. Spalding KL, Arner E, Westermark PO, Bernard S, Buchholz BA, Bergmann $\mathrm{O}$, et al. Dynamics of fat cell turnover in humans. Nature. 2008;453:783-7.

4. Faust IM, Johnson PR, Stern JS, Hirsch J. Diet-induced adipocyte number increase in adult rats: a new model of obesity. Am J Physiol. 1978;235:E279-86.

5. Cristancho AG, Lazar MA. Forming functional fat: a growing understanding of adipocyte differentiation. Nat Rev Mol Cell Biol. 2011;12:722-34.

6. Rosen ED, MacDougald OA. Adipocyte differentiation from the inside out. Nat Rev Mol Cell Biol. 2006;7:885-96.

7. Akune T, Ohba S, Kamekura S, Yamaguchi M, Chung UI, Kubota $\mathrm{N}$, et al. PPARgamma insufficiency enhances osteogenesis through osteoblast formation from bone marrow progenitors. $\mathbf{J}$ Clin Invest. 2004;113:846-55.

8. Farmer SR. Transcriptional control of adipocyte formation. Cell Metab. 2006;4:263-73.

9. Tontonoz P, Spiegelman BM. Fat and beyond: the diverse biology of PPARgamma. Annu Rev Biochem. 2008;77:289-312.

10. Lefterova MI, Zhang Y, Steger DJ, Schupp M, Schug J, Cristancho A, et al. PPARgamma and C/EBP factors orchestrate adipocyte biology via adjacent binding on a genome-wide scale. Genes Dev. 2008;22:2941-52.

11. Smas CM, Chen L, Zhao L, Latasa MJ, Sul HS. Transcriptional repression of pref-1 by glucocorticoids promotes 3T3-L1 adipocyte differentiation. J Biol Chem. 1999;274:12632-41.

12. van Beekum O, Fleskens V, Kalkhoven E. Posttranslational modifications of PPAR-gamma: fine-tuning the metabolic master regulator. Obesity. 2009;17:213-9.

13. Kim JH, Park KW, Lee EW, Jang WS, Seo J, Shin S, et al. Suppression of PPARgamma through MKRN1-mediated ubiquitination and degradation prevents adipocyte differentiation. Cell Death Differ. 2014;21:594-603.

14. Ahmadian M, Suh JM, Hah N, Liddle C, Atkins AR, Downes M, et al. PPARgamma signaling and metabolism: the good, the bad and the future. Nat Med. 2013;19:557-66.

15. Hou Y, Moreau F, Chadee K. PPARgamma is an E3 ligase that induces the degradation of NFkappaB/p65. Nat Commun. 2012;3:1300. 
16. Hou Y, Gao J, Xu H, Xu Y, Zhang Z, Xu Q, et al. PPARgamma E3 ubiquitin ligase regulates MUC1-C oncoprotein stability. Oncogene. 2014;33:5619-25.

17. Gandhi UH, Kaushal N, Ravindra KC, Hegde S, Nelson SM, Narayan V, et al. Selenoprotein-dependent up-regulation of hematopoietic prostaglandin D2 synthase in macrophages is mediated through the activation of peroxisome proliferatoractivated receptor (PPAR) gamma. J Biol Chem. 2011;286:27471-82.

18. Kim CY, Kim KH. Dexamethasone-induced selenoprotein $\mathrm{S}$ degradation is required for adipogenesis. $\mathrm{J}$ Lipid Res. 2013;54:2069-82.

19. Walter P, Ron D. The unfolded protein response: from stress pathway to homeostatic regulation. Science. 2011;334:1081-6.

20. Han J, Murthy R, Wood B, Song B, Wang S, Sun B, et al. ER stress signalling through eIF2alpha and CHOP, but not IRE1alpha, attenuates adipogenesis in mice. Diabetologia. 2013;56:911-24.

21. Lee JH, Kwon JH, Jeon YH, Ko KY, Lee SR, Kim IY. Pro178 and Pro183 of selenoprotein $S$ are essential residues for interaction withp97(VCP) during endoplasmic reticulum-associated degradation. J Biol Chem. 2014;289:13758-68.

22. Lee JH, Park KJ, Jang JK, Jeon YH, Ko KY, Kwon JH, et al. Selenoprotein S-dependent Selenoprotein K binding top97(VCP) protein is essential for endoplasmic reticulum-associated degradation. J Biol Chem. 2015;290:29941-52.

23. Cho YM, Kwak SN, Joo NS, Kim DH, Lee AH, Kim KS, et al. Xbox binding protein 1 is a novel key regulator of peroxisome proliferator-activated receptor gamma2. FEBS J. 2014;281:5132-46.

24. Kryukov GV, Castellano S, Novoselov SV, Lobanov AV, Zehtab $\mathrm{O}$, Guigo R, et al. Characterization of mammalian selenoproteomes. Science. 2003;300:1439-43.

25. Kim KH, Gao Y, Walder K, Collier GR, Skelton J, Kissebah AH. SEPS1 protects RAW264.7 cells from pharmacological ER stress agent-induced apoptosis. Biochem Biophys Res Commun. 2007;354:127-32.

26. Du S, Zhou J, Jia Y, Huang K. SelK is a novel ER stress-regulated protein and protects HepG2 cells from ER stress agent-induced apoptosis. Arch Biochem Biophys. 2010;502:137-43.

27. Jang JK, Park KJ, Lee JH, Ko KY, Kang S, Kim IY. Selenoprotein $\mathrm{S}$ is required for clearance of $\mathrm{C} 99$ through endoplasmic reticulum-associated degradation. Biochem Biophys Res Commun. 2017;486:444-50.

28. Kelly E, Greene CM, Carroll TP, McElvaney NG, O’Neill SJ. Selenoprotein S/SEPS1 modifies endoplasmic reticulum stress in $\mathrm{Z}$ variant alpha1-antitrypsin deficiency. J Biol Chem. 2009;284:16891-7.

29. Shchedrina VA, Everley RA, Zhang Y, Gygi SP, Hatfield DL, Gladyshev VN. Selenoprotein K binds multiprotein complexes and is involved in the regulation of endoplasmic reticulum homeostasis. J Biol Chem. 2011;286:42937-48.

30. Cnop M, Foufelle F, Velloso LA. Endoplasmic reticulum stress, obesity and diabetes. Trends Mol Med. 2012;18:59-68.

31. Li SF, Guo L, Qian SW, Liu Y, Zhang YY, Zhang ZC, et al. G9a is transactivated by $\mathrm{C} / \mathrm{EBPbeta}$ to facilitate mitotic clonal expansion during 3T3-L1 preadipocyte differentiation. Am J Physiol Endocrinol Metab. 2013;304:E990-8.

32. Zhao Y, Gao J, Lu F. Human adipose-derived stem cell adipogenesis induces paracrine regulation of the invasive ability of MCF-7 human breast cancer cells in vitro. Exp Ther Med. 2013;6:937-42.

33. Nolte RT, Wisely GB, Westin S, Cobb JE, Lambert MH, Kurokawa R, et al. Ligand binding and co-activator assembly of the peroxisome proliferator-activated receptor-gamma. Nature. 1998;395:137-43.
34. Tasdelen I, Berger R, Kalkhoven E. PPARgamma regulates expression of carbohydrate sulfotransferase 11 (CHST11/C4ST1), a regulator of LPL cell surface binding. PLoS ONE. 2013;8: e64284.

35. Noh OJ, Park YH, Chung YW, Kim IY. Transcriptional regulation of selenoprotein $\mathrm{W}$ by MyoD during early skeletal muscle differentiation. J Biol Chem. 2010;285:40496-507.

36. Jeon YH, Park YH, Lee JH, Hong JH, Kim IY. Selenoprotein W enhances skeletal muscle differentiation by inhibiting TAZ binding to 14-3-3 protein. Biochim Biophys Acta. 2014;1843:1356-64.

37. Zhang Y, Chen X. Reducing selenoprotein P expression suppresses adipocyte differentiation as a result of increased preadipocyte inflammation. Am $\mathrm{J}$ Physiol Endocrinol Metab. 2011;300:E77-85.

38. Dreher I, Schutze N, Baur A, Hesse K, Schneider D, Kohrle J, et al. Selenoproteins are expressed in fetal human osteoblast-like cells. Biochem Biophys Res Commun. 1998;245:101-7.

39. Yan J, Fei Y, Han Y, Lu S. Selenoprotein O deficiencies suppress chondrogenic differentiation of ATDC5 cells. Cell Biol Int. 2016;40:1033-40.

40. Sha $\mathrm{H}, \mathrm{He} \mathrm{Y}$, Chen $\mathrm{H}$, Wang $\mathrm{C}$, Zenno A, Shi H, et al. The IRE1alpha-XBP1 pathway of the unfolded protein response is required for adipogenesis. Cell Metab. 2009;9:556-64.

41. Miyahara T, Schrum L, Rippe R, Xiong S, Yee HF Jr., Motomura $\mathrm{K}$, et al. Peroxisome proliferator-activated receptors and hepatic stellate cell activation. J Biol Chem. 2000;275:35715-22.

42. Ito T, Ito N, Bettermann A, Tokura Y, Takigawa M, Paus R. Collapse and restoration of MHC class-I-dependent immune privilege: exploiting the human hair follicle as a model. Am J Pathol. 2004;164:623-34.

43. Majdalawieh A, Ro HS. PPARgamma1 and LXRalpha face a new regulator of macrophage cholesterol homeostasis and inflammatory responsiveness, AEBP1. Nucl Recept Signal. 2010;8:e004.

44. Lehrke M, Lazar MA. The many faces of PPARgamma. Cell . 2005;123:993-9.

45. Hauser S, Adelmant G, Sarraf P, Wright HM, Mueller E, Spiegelman BM. Degradation of the peroxisome proliferator-activated receptor gamma is linked to ligand-dependent activation. J Biol Chem. 2000;275:18527-33.

46. Jacobson AD, Zhang NY, Xu P, Han KJ, Noone S, Peng J, et al. The lysine 48 and lysine 63 ubiquitin conjugates are processed differently by the $26 \mathrm{~s}$ proteasome. J Biol Chem. 2009;284:35485-94.

47. Xu P, Duong DM, Seyfried NT, Cheng D, Xie Y, Robert J, et al. Quantitative proteomics reveals the function of unconventional ubiquitin chains in proteasomal degradation. Cell . 2009;137:133-45.

48. Chau V, Tobias JW, Bachmair A, Marriott D, Ecker DJ, Gonda $\mathrm{DK}$, et al. A multiubiquitin chain is confined to specific lysine in a targeted short-lived protein. Science. 1989;243:1576-83.

49. Finley D, Sadis S, Monia BP, Boucher P, Ecker DJ, Crooke ST, et al. Inhibition of proteolysis and cell cycle progression in a multiubiquitination-deficient yeast mutant. Mol Cell Biol. 1994;14:5501-9.

50. David Y, Ternette N, Edelmann MJ, Ziv T, Gayer B, Sertchook R, et al. E3 ligases determine ubiquitination site and conjugate type by enforcing specificity on E2 enzymes. J Biol Chem. 2011;286:44104-15.

51. Verma S, Hoffmann FW, Kumar M, Huang Z, Roe K, Nguyen$\mathrm{Wu}$ E, et al. Selenoprotein K knockout mice exhibit deficient calcium flux in immune cells and impaired immune responses. $\mathrm{J}$ Immunol. 2011;186:2127-37.

52. Basen-Engquist K, Chang M. Obesity and cancer risk: recent review and evidence. Curr Oncol Rep. 2011;13:71-6. 
53. Picard F, Richard D, Huang Q, Deshaies Y. Effects of leptin adipose tissue lipoprotein lipase in the obese ob/ob mouse. Int $\mathbf{J}$ Obes Relat Metab Disord. 1998;22:1088-95.

54. Szasz AM, Lanczky A, Nagy A, Forster S, Hark K, Green JE, et al. Cross-validation of survival associated biomarkers in gastric cancer using transcriptomic data of 1065 patients. Oncotarget. 2016;7:49322-33.

55. Lanczky A, Nagy A, Bottai G, Munkacsy G, Szabo A, Santarpia L, et al. miRpower: a web-tool to validate survival-associated miRNAs utilizing expression data from 2178 breast cancer patients. Breast Cancer Res Treat. 2016;160:439-46.

56. Kim KS, Choi HW, Yoon HE, Kim IY. Reactive oxygen species generated by NADPH oxidase 2 and 4 are required for chondrogenic differentiation. J Biol Chem. 2010;285:40294-302.

57. Park YH, Jeon YH, Kim IY. Selenoprotein W promotes cell cycle recovery from $\mathrm{G} 2$ arrest through the activation of CDC25B. Biochim Biophys Acta. 2012;1823:2217-26.
58. Ballar P, Shen Y, Yang H, Fang S. The role of a novel p97/valosincontaining protein-interacting motif of gp78 in endoplasmic reticulum-associated degradation. J Biol Chem. 2006;281: 35359-68.

59. Park S, Yoo S, Kim J, An HT, Kang M, Ko J. 14-3-3beta and gamma differentially regulate peroxisome proliferator activated receptor gamma2 transactivation and hepatic lipid metabolism. Biochim Biophys Acta. 2015;1849:1237-47.

60. Boukhzar L, Hamieh A, Cartier D, Tanguy Y, Alsharif I, Castex M, et al. Selenoprotein $\mathrm{T}$ exerts an essential oxidoreductase activity that protects dopaminergic neurons in mouse models of Parkinson's disease. Antioxid Redox Signal. 2016;24:557-74.

61. Jeong GU, Park IH, Ahn K, Ahn BY. Inhibition of hepatitis B virus replication by a dNTPase-dependent function of the host restriction factor SAMHD1. Virology. 2016;495:71-8. 